\title{
A matter of choice: A critical discourse analysis of ECEC policy in Canada's 2006 federal election
}

\author{
Occasional Paper No. 25
}

\author{
Brooke Richardson \\ Master of Arts \\ Early Childhood Studies \\ Ryerson University \\ December 14, 2011
}


A matter of choice: A critical discourse analysis of ECEC policy in Canada's 2006 federal election.

Brooke Richardson

Occasional Paper No. 25

December 14, 2011

iv, $71 \mathrm{pp}$.

ISBN 978-1-896051-52-9

Childcare Resource and Research Unit

225 Brunswick Avenue

Toronto ON M5S 2M6, Canada

TEL: 416-926-9264

FAX: 416-971-2139

EMAIL: contactus@ childcarecanada.org

WEBSITE: www.childcarecanada.org

This Occasional Paper No. 25 is available from the Childcare Resource and Research Unit in an online format only. This paper was submitted by the author as a Major Research Paper to Ryerson University in partial fulfillment of the requirements for the degree of Master of Arts in the Program of Early Childhood Studies. It may be used for educational or research purposes with appropriate citation or with the permission of the author.

The points of view represented in CRRU's publications are those of their authors and do not necessarily represent the opinions of CRRU or its funders. 


\begin{abstract}
This paper used a Critical Discourse Analysis (CDA) to analyze the representation of Early Childhood Education and Care (ECEC) in the 2006 federal election in Canada. Using Fairclough's approach to CDA, the study analyzed written documents including newspaper articles from The Globe and Mail and The National Post, the policy platforms of the Liberal and Conservative parties, and political speeches from party leaders. The "choice" discourse was found to be dominant in the majority of texts examined. A dominant discourse is one that is created and sustained by those with power thus contributing to hegemony in society. Three textual and discourse processes were found to legitimize the "choice" discourse and contribute to its dominance: rationalization, nominalization and conversationalization. It is suggested that the language used in public documents throughout this election and the subsequent dominance of the "choice" discourse may have had a significant impact on citizens' understanding and appreciation of the complexities of ECEC in Canada.
\end{abstract}




\section{Table of Contents}

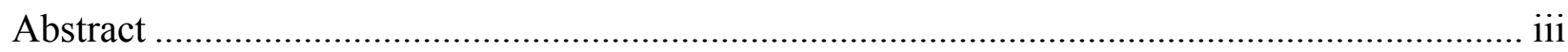

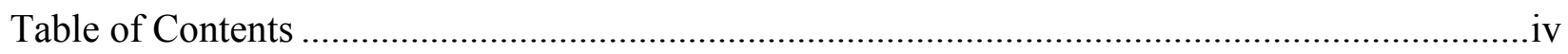

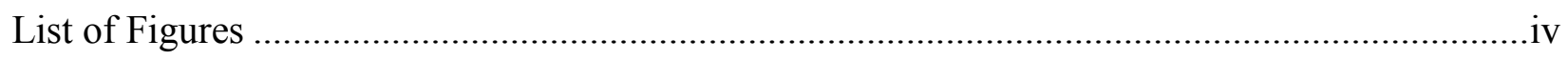

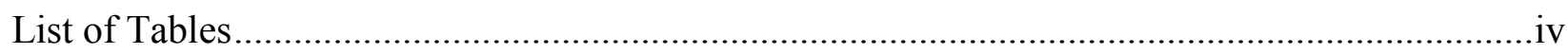

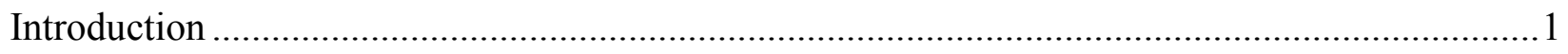

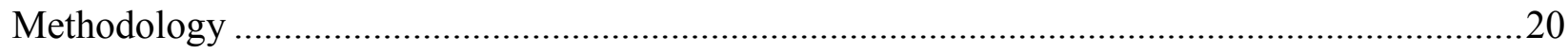

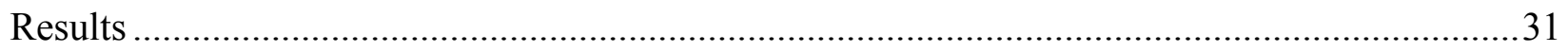

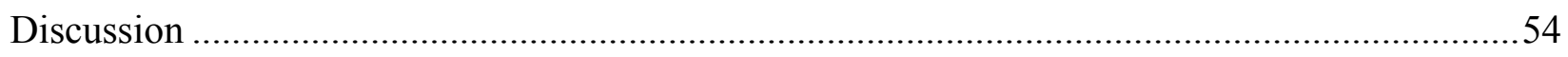

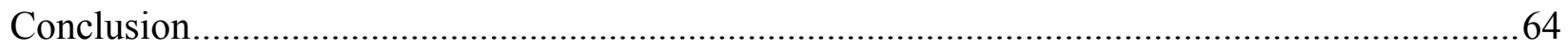

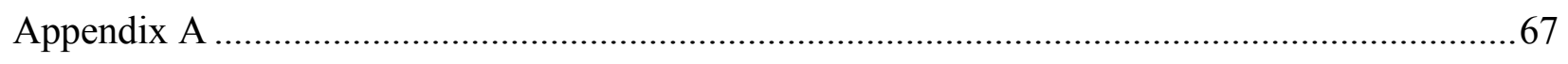

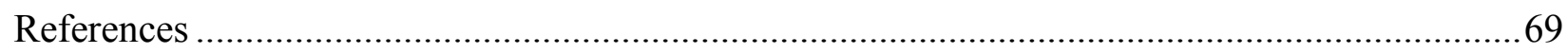

List of Figures

Figure 1: Fairclough's Model of Critical Discourse Analysis .............................................28

\section{List of Tables}

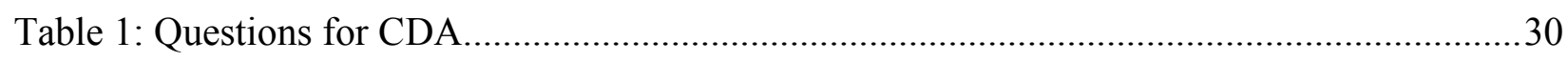

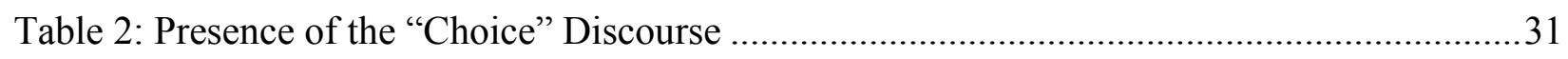




\section{Introduction}

Politics is about real-world power and the way we understand morality. The bitterness in politics is partly about who has power and patronage and the control of money and resources that goes with political power. But the wider and deeper emotionality and bitterness is about morality, about whose moral system will rule. This is what public politic discourse is mainly about. And public discourse has an enormous effect upon the outcome of elections. (Lakoff, 2009, p.110)

The political campaign is always about more than the easily identifiable issues at hand. Key issues and the policies proposed to address these issues are based in deep-seated values, beliefs and ideologies regarding how the individual, family, society and government should or should not function. Whether created by politicians, political parties or the media, texts produced throughout the political campaign reflect these values. As such, the texts to which a population is exposed, and, more specifically the language used to portray ideas, plays a significant role in citizens' understanding, appreciation and beliefs about the issue. The more one sees his or her own ideologies reflected in texts of a given politician or political party, the more likely he or she is to vote for this party (Lakoff, 2006).

This paper examines how the balance of state, family and market responsibility for children's well-being was portrayed and discussed throughout the 2006 federal election in Canada. This election brought forth what has been described as two "diametrically opposed" (Friendly, as quoted by Rhinehart, 2005) Early Childhood Education and Care (ECEC) policy initiatives. The first of these, the Early Learning and Child Care (ELCC) Foundations program, was a national ECEC strategy proposed by the Liberal government. The ELCC Foundations program was in its initial stages of development at the time of the election. The alternative, the Universal Child Care Benefit (UCCB), was proposed by the Conservative party and would provide a taxable income supplement of $\$ 100$ a month paid directly to parents for every child under six. This paper will examine how these different policy proposals were framed and marketed to parents and Canadian citizens through the language and discourses used in party platforms, media reports and speeches by party leaders.

An underlying assumption of this paper is that the political campaign often delivers the ultimate sales pitch for the implementation or revision of social policy. Social policy, including its inherent values and beliefs, becomes a complex conglomerate of ideas being sold to the people 
in an effort to secure the maximum number of votes. Yet consumers of social policy and related programs (i.e., Canadian citizens) are arguably only aware of social policy proposals as presented through one-way, mediated texts. An informed voter must be critically aware of how information is portrayed, what is included and excluded, and who controls the conversation. The concern is that information disseminated through the majority of campaign texts does not undergo such critical analysis leaving voters only partially informed. Key ideas, pieces of information, important details of existing policy and new policy proposals often are left unaddressed unbeknownst to voters. When this occurs, the democratic process on which Canada prides itself is undermined. Too often the policies related to childcare issues are not determined by the needs of parents or children, but rather by politicians who are most interested in getting elected. Successful politicians recognize the importance of media reports and election networks during an election campaign.

This paper attempts to critically analyze the one-way, mediated texts related to ECEC policy that Canadian citizens were exposed to throughout the 2006 federal election. Newspaper articles from two of Canada's prominent national newspapers, The Globe and Mail and The National Post, the policy platforms themselves and key political speeches made by party leaders underwent a critical discourse analysis (Fairclough, 2003) in an attempt to identify how the language used and the manner in which it was used may have influenced consumers' understanding and appreciation of the proposed ECEC policies. Because ECEC services and policy in Canada continue to lag in comparison to those of other developed countries (UNICEF, 2008) such an analysis is long overdue.

A key component of CDA is the identification of the ideological foundations on which discourse is built. Ideological foundations permeate social policy proposals and decisions yet are rarely explicitly spoken or identified. Instead, values and beliefs infiltrate texts unknowingly to consumers of the texts. The delicate balance between the responsibilities of citizens, the state and the market is the main ideological concern in social policy debates. Indeed, whether or not a state is considered a welfare state is dependent on its resolution of this balance. Esping-Anderson (1999) names three different models of the welfare state - each weighing the responsibilities of the state, market and citizens differently. These are termed the conservative, liberal and social democratic models of welfare regimes in advanced capitalist countries. The models provide an 
overarching framework for this analysis. The discourses explored throughout this paper will be related back to the three models of the welfare state.

The parent "choice" in ECEC discourse, which is central to this paper and referred to as the "choice" discourse throughout, received a great deal of attention during the 2006 election. This discourse is based on the underlying assumption that parents should be exclusively responsible for their children's well-being and opportunity with very little state interference. One direct consequence of such an ideology is that it favours limiting government intervention to money directly distributed to parents to spend on ECEC however they wish. This approach to a parent's "right to choose" what, when, where and by whom child care is provided reflects the belief that parents bear the full responsibility for their child's well-being.

This research will attempt to answer the following three questions:

1. How prevalent was the "choice" discourse in the 2006 election? Was it dominant?

2. In addition to the "choice" discourse, what other discourses were used to support and/or refute the proposed ECEC policies?

3. What textual and discourse processes were used to control the dominant discourse(s)?

\section{Historical Context of ECEC in Canada}

Political interest in the care and education of young children in Canada has waxed and waned since the creation of our country. Although kindergarten and other childcare-like programs existed as early as the 1850 's, it was not until World War II that childcare received federal social policy attention. During the war, federally funded childcare centres were created to enable women to work in essential industries while men were at war. Despite the fact that this funding for childcare centres was abruptly cut after the war, women had entered the workforce and a demand for childcare had been created. With no federal funding to create and supply childcare services, the for-profit sector grew. By 1960, $75 \%$ of licensed spaces were operated by the forprofit sector (Friendly \& Prentice, 2009).

Beginning in the late 1960's and 1970's the Canada Assistance Plan (CAP) facilitated federal social spending. This open-ended, 50/50 cost-sharing with the provinces indirectly supported the growth of childcare since provinces were able to access CAP funding to subsidize the cost of childcare for families who were deemed to be "in need". Other initiatives, such as paid 
maternity leave and the Child Care Expense Deduction were introduced in the 1970's largely as a result of the rising women's equality movement. In the 1980's a Task Force on Child Care appointed by Prime Minister Trudeau recommended a universal, publicly funded, high-quality, non-profit childcare system. The Conservative party, which formed the government in 1984, did not support this initiative and launched its own Special Committee on Child Care. This committee proposed funding for-profit centres and increasing tax deductions for parents to help offset the cost of childcare. Most of the committee's proposals died with the next federal election (Friendly \& Prentice, 2009).

A new Liberal government came to power again in the early 1990's and the mechanism of social funding was fundamentally altered. In 1995, CAP was replaced with the Canada Health and Social Transfer (CHST). The CHST allowed more sovereignty for the provinces regarding how they would spend federal money allocated to social spending. Two key differences between CAP and the CHST are that the CHST is a limited amount of money and, as it was a general block fund rather than a cost-sharing with specific childcare provisions, it committed no direct funding to ECEC. ECEC essentially fell off the political agenda until 2003 when the Multilateral Framework Agreement on Early Learning and Child Care (MFA) was created. The MFA committed \$1 billion spread over five years to support provincially-run regulated ECEC programs. All provinces, except Quebec, signed on (Friendly \& Prentice, 2009).

In the 2004 election, the Liberal government promised \$5 billion towards the ELCC Foundations program, which had the goal of establishing the groundwork for a national, quality, and accessible, universal early learning and childcare program in collaboration with the provinces. The Liberals secured a minority government and pursued this initiative until the fall of 2005 when another federal election was called. It was in the 2005-2006 Federal election that the Conservatives proposed the Universal Child Care Benefit (UCCB) to replace the ELCC Foundations program that was still in its beginning stages. The Conservatives won a minority government in 2006 and one of the first announcements made by the Harper government was the cancellation of the ELCC Foundations program and the implementation of the UCCB.

As had always been the case in Canada, ECEC following the 2006 election was described as lacking cohesiveness, quality and accessibility (OECD, 2006; UNICEF, 2008). Canada had, and still has, yet to develop and implement any national policy regarding ECEC. With the much 
needed expansion of ECEC services slowing down after the cancellation of the ELCC Foundations program it was not surprising that Canada met only one of ten UNICEF benchmarks for ECEC services, scoring the lowest of 25 developed countries in 2008 (UNICEF, 2008).

Such a sequence of events emphasizes the fragility of social policy initiatives through successive governments with different ideological foundations. This paper examines the dramatic shift in ECEC policy and funding to ECEC services that happened largely as a result of proposed ECEC policy initiatives during and following the 2006 election. Although ECEC was by no means the only policy issue on the table during the 2006 election, it was in the foreground receiving much more attention than in previous elections or any elections that have taken place since then.

\section{Conceptualization of the Liberal Welfare State}

It is fundamental to understand how a liberal welfare state such as Canada is conceptualized before discussing why ECEC is important in our country. Esping-Anderson (1999) categorizes modern welfare states into conservative, liberal or social democratic regimes. These different regimes weigh the responsibility for citizens' well-being and opportunity more or less heavily between the state, family and market.

According to Esping-Anderson, a classic conservative welfare regimes places citizens in a subordinate role to those with authority; in conservative welfare regimes, the church often reinforces (and enforces) traditional family values. Status differentials permeate a conservative welfare regime where rights are awarded to those of high status and power. Underlying the conservative regime is the idea that, "individuals are not meant to compete or struggle, but to subordinate self-interest to recognize authority and prevailing institutions" (Esping-Anderson, p.38). Social policies that facilitate the well-being and opportunities of citizens are often nonexistent in a conservative welfare regime. At most, and only in some circumstances, the state may intervene when family resources are depleted. Alternatively, some conservative regimes may award citizens social rights, but only on the condition of their loyalty and faithfulness to the powerful individuals and institutions of the state.

At the other end of the spectrum is the social democratic regime where the state plays a strong mediating force between the market and the family in order to maximize the opportunity and well-being of its citizens. Esping-Anderson (1999) describes such a state as providing "a 
basic floor beneath which no one would be allowed to fall" (p.46). Social programs are generally universal in nature as opposed to means-based. Although capitalism still reigns, social rights are prioritized through policies that promote the decommodification of goods and services. In other words, the welfare of citizens is considered a "right" as opposed to a reward.

An example of a social democratic country would be Sweden. In 2006, Sweden spent $28.9 \%$ of its GDP on social expenditures, with $2 \%$ of the GDP going directly to ECEC services (OECD, 2006). Not surprisingly, quality ECEC services are available to all children and families in Sweden with parents paying less than $10 \%$ of the cost of the services. A direct consequence of such significant spending is one of the lowest international child poverty rates $-4.2 \%$ in 2006 (OECD, 2006). Although the market is still an important aspect of the economy in Sweden, the state plays a significant role in intervening in the well-being of families and citizens.

The third model of welfare capitalism is the liberal state. The modus operandi in a pure liberal regime is that citizens share an equal opportunity for "success" (Esping-Aderson, 1999). A liberal ideology is based on the assumption that all who want to work will have jobs and their welfare will thus be secured. Indeed, the market is seen as "emancipatory" (Esping-Anderson, 1999, p.42) in a pure liberal regime. Individual competition is viewed as healthy and a key motivator for individuals to get educated, work, and lead productive lives. Social stratification achieved by the marketplace is considered just because it "mirrors effort, motivation, adeptness and self-reliance" (Esping-Anderson, p.62). State intervention in the market is warranted only to the extent that it reduces the pathology of the marketplace in order to protect the capitalist system (Taylor, 2007). Direct state assistance to the people is limited to the poor and desolate and usually comes at the cost of negative social stigma.

Esping-Anderson (1999) explains that liberalism in its most pure form went through a reform in the early 1900's. Whereas in the past a pure liberal regime attempted to "squeeze the last drop of sweat from the worker" (Esping-Anderson, 1999, p.63) reform liberalism recognized that the emerging economy was coming to value human capital and a bureaucracy. The idea that there should be "help to self-help" emerged. Reform liberals endorse a "firm commitment to the market with a belief that its salvage required greater social responsibilities" (Esping-Anderson, 1999, p.63). An example of policy in line with reform liberalism is the Canadian government's commitment to funding post-secondary education. This funding, which is essential to the 
establishment and operation of post-secondary institutions, levels the playing field for citizens. Reform liberalism allows the government to step in to reduce the pathologies the marketplace inevitably creates while still keeping benefits to a minimum so as to encourage fiscal responsibility.

During the post World War II years, social policy in Canada expanded in line with a reform liberal ideology. Social policies to support initiatives like unemployment insurance, medicare, and public education were created. In time, the term "liberal" came to be associated with a state that interfered with the role of the market in determining citizens' well-being and opportunity. A neo-liberalist ideology reiterated the importance of market supremacy. Neoliberalism encourages the state to "withdraw as far as possible from economic management and social provision" (Taylor, 2007). Neo-liberalism brought attention back to the fundamental liberal values that liberalism originally preached: individual responsibility, market supremacy, and above all, capitalism.

No country neatly fits into any one of these categories, given that governments and policy are a combination of different ideologies that are constantly in a state of flux. Having said this, Canada is best characterized as a reform liberal state for much of the post-World War II period. In Canada, social policy supports programs such as employment insurance, basic health insurance, public primary and secondary education, as well as numerous other programs that seemingly enable "help to self-help". Ultimately however, one's well-being can be considered to be strongly dependent on success in the marketplace. This dependence on the market is evident in the insufficient social spending on ECEC services. In 2006, total spending on ECEC services amounted to than less $0.3 \%$ of our GDP (OECD, 2006). These figures do not appear to have changed significantly in 2011. There are limited state funded programs and/or fee subsidies, but the well-being of families and children in the realm of ECEC services remains primarily a private responsibility of the family.

Prior to Harper's election, the Conservative party was best represented as a rightist liberal model of welfare capitalism. Today the Conservative Party could be considered a blend of neoliberalism and social conservatism given the emphasis on reducing the role of the state with a strong overlay of social conservative values - i.e., the traditional family. On the other end of the spectrum, the New Democratic Party historically has favoured policies more in line with social 
democratic values. The Liberal party would fall somewhere in the middle, but generally more heavily leaning towards reform liberalism as defined above.

"Choice" is a phenomenon that is endorsed in a liberal welfare state as choice is considered the reward for market success: those who work hard will obtain the financial means to be able to go out and purchase whatever goods and services they choose. A basic level of provision may or may not exist. If this is not considered adequate one must assume the responsibility for purchasing what is required. For example, primary and secondary public education is available to all of Canada's children and youth. Families who are most successful in the market have the added option of sending their children to private schools. This may be considered more ideal for a family if it is perceived to provide a higher quality of education, provide an education that is more in line with their values, or is simply more convenient. Regardless of the reasons behind the choice, the fact that this choice exists is solely due to the family's success in the market. This education is not an option for families who have children who would significantly benefit from the learning environment of a private school but do not have the resources to afford it.

\section{Why is ECEC Policy Important?}

ECEC policy is of particular concern to all Canadians since the programs created (or not created) by such policy will have short-term and long-term effects on Canadian children, parents and society in general. Comprehensive ECEC policy on a national scale has the potential to ensure the ongoing provision of high quality, accessible ECEC services for all of Canada's children and families. Three prominent approaches supporting state investment in ECEC policy include the economic, human capital and children's rights rationales. These rationales underscore the discourses that permeate the documents to be analyzed.

\section{The Economic Rationale}

Key economists and academics specializing in ECEC argue that in Canada "the incremental social and economic benefits of a publicly financed system of early learning and child care services for children aged two to five exceed the costs by a margin of at least two to one" (Cleveland and Krashinsky, 2004, p.2). Cleveland and Krashinsky (1998) describe public investment as being "prudent and productive" (p.5) due to its significant benefits within the public sphere. 
Increased maternal employment played a significant role in Cleveland and Krashinsksy's cost-benefit analysis of public dollars invested in ECEC. A direct economic effect of increased maternal employment is an increase in taxes paid. This can be seen as an outcome of the program and a potential factor in the increased wealth of the state. More recently, increased maternal employment has been observed in Quebec following the implementation of the provincial \$7 a day childcare provision. The percentage of mothers of children under six who are employed in Quebec has risen 11\% since the inception of the program (Fortin, P., Godbout, L., \& St-Cerny, S., 2011). This can be compared to the $4 \%$ increase in maternal employment for children under six in Ontario during the same period. Similarly, employment for mothers with children between the ages of 6 and 15 has risen 14\% in Quebec as compared to 4\% in Ontario since Quebec's program was initiated (Fortin et al, 2011).

A concept called a multiplier has been used to measure the short-term economic activity investment a program stimulates. Programs that are high multipliers are especially good at stimulating job creation. When compared to education of older children and youth, construction, health, and various other sectors, "Multiplier estimates for Canada show that the ECEC sector has one of the highest multipliers of all major sectors" (Child Care Human Resources Sector Council, 2009, p.39). This report, commissioned by the Child Care Human Resources Sector Council and authored by Robert Fairholm, calculates a $\$ 2.54$ return for every dollar invested in ECEC in Canada.

\section{A Human Capital Rationale}

A human capital rationale places emphasis on the monetary gain to the individual and society that optimizing a child's developmental potential offers. In essence, a human capital rationale for ECEC services suggests that we can "build a better baby" who will grow up to be a more valuable asset to his or her family and/or society. In 1999, an influential literature review of research summarizing the social, emotional, linguistic and cognitive processes that take place in the early years contributed to the popularity of this rationale (McCain \& Mustard, 1999). This report reinforced the popular idea that high quality, developmentally appropriate stimulation during early critical periods of development is essential to maximize potential in all developmental domains. 
Research related to brain development is often cited to support a human capital rationale. Shonkoff and Phillips (2000), authors of a comprehensive book representing the work of a highpowered panel of neuroscientists, educators and psychologists support the idea that in certain (generally extreme) circumstances, enriched sensory experiences in the early years may have an impact on brain development. This report also emphasizes that intervention programs for children who are considered at-risk can help to mediate the negative impact of poverty and trauma if the programming is high quality and that the quality of ECEC programs is of high importance in multiple developmental domains for all children.

McCain and Mustard's (1999) report also refers to a large body of research that demonstrates a positive relationship between nurturing and consistent caregiving and adaptive adult coping responses to stress. This research is often interpreted to imply that investing in rich, quality early learning and care experiences for young children will pay off in human capital: that children will be "smarter", that there will be lower rates of delinquency, and that as adults they will be better adjusted. Some may take this argument a step further suggesting that these adults will be better prepared to effectively parent another generation. In this paradigm, the cash value of such outcomes is seen as a prudent reason to invest in ECEC.

\section{A Child's Right Rationale}

A different justification for a quality ECEC system, though used far less frequently in Canada, is the view that ECEC services should be seen as a child's right or a basic entitlement. This point of view regards children as citizens, with voices that are valued and respected. Canada was one of the first countries to ratify the United Nations Convention on the Rights of the Child (CRC) in 1990 guaranteeing basic rights to children, including childcare, though little progress has been made towards keeping these promises (Friendly, 2006). Article 18 in the Convention states: "State parties shall take all appropriate measures to ensure that children of working parents have the right to benefit from child-care services and facilities for which they are eligible" (Committee on the Rights of the Child, 1990, p.5). Although a child rights approach is seldom cited in Canada as adequate justification for public investment in quality ECEC services, it is a key rationale used by other countries and in international analysis by such groups as the United Nations Children's Funds (UNICEF). These rationales underscore the discourses that permeate the documents to be analyzed. 


\section{An Alternative Viewpoint - ECEC Policy Is Not Preferred}

\section{The Traditional Family Rationale}

Others would argue that ECEC policy and services are not in the best interests of children and families. An underlying belief supporting this rationale is that providing children with the optimal experiences and care during the early years is the sole responsibility of parents and the family. In fact, firm supporters of the traditional family rationale may go as far as to suggest that it is not good for children to be cared for by anyone other than the parents. According to the traditional rationale, the family is conceptualized as a married mother, father and child(ren). While the father generally plays the role of breadwinner, the mother is primarily responsible for care of the children regardless of whether or not she is employed outside of the home. Although the demographics in our country are changing and the male breadwinner family now constitutes the minority of Canadian families, this traditional family rationale still has a strong ideological hold on some of Canada's citizens and is reflected in the politics of the Conservative Party.

\section{Policy Consequences of the Traditional Family Rationale - The Market Model}

One direct consequence of the traditional family rationale is restricted government involvement in ECEC services. In this approach, public funding tends to be quite limited; public funding that is available is often restricted to demand-side funding approaches such as tax breaks and/or cash or vouchers that go directly to parents rather than to funding for the development of the larger infrastructure necessary for the creation of quality ECEC spaces. Whether or not such tax cuts and/or cash payments should be considered ECEC policy is questionable as there is no guarantee that money reimbursed through tax cuts or acquired through benefits will be spent on ECEC services. There are many ways that parents may spend or save this money, such as placing it in an RESP or putting it towards extra-curricular activities. Furthermore, there is no guarantee that such money will directly benefit the child.

With limited government involvement in ECEC services, the market tends to become the prime provider of childcare. That the market is a poor provider of quality ECEC has been noted by the Organization for Economic Co-operation and Development (OECD):

A public supply side investment model, managed by public authorities, brings more uniform quality and superior coverage of childhood populations than parent subsidy models....the review suggests that direct public funding of services brings, in the majority of countries reviewed, more effective control, advantages 
of scale, better national quality, more effective training for education and higher degree of equality and access and participation than consumer subsidy models (OECD, 2006, p.114).

While a market approach to childcare does not necessarily mean that childcare is solely operated for profit, a key practical consequence is usually heavy reliance on for-profit programs. Close to home, Canadian research has consistently found commercial centres, the epitome of market-produced child care, to be of statistically significant poorer quality than not-for-profit centres (See a review of this literature in Cleveland and Krashinksy, 2004).

In child care centers in Canada, commercial centers are disproportionately represented amongst the lower quality classrooms and nonprofits are disproportionately represented amongst the good quality classrooms (Cleveland, Forer, Hyatt, Japel, Krashinsky, 2007, p. 42).

One hypothesis as to why not-for-profits provide superior quality care is that they receive greater resources through grants and government funding. However, Cleveland and Krashinsky note that when financial resources available to centres were held constant for both auspices, notfor-profit centres still demonstrated superior quality services (Cleveland and Krashinsky, 2004a). Other hypotheses raised to account for the consistent differences are that not-for-profits legally must reinvest surpluses back into the centre and that boards of directors manage them without a financial interest in the organization. Vincent and Ball (2006) argue that ECEC services are unique in that non-market commodities, such as loyalty, trust and affection, play a significant role in the services chosen. Given that these are based on an intuitive feeling rather than any objective measurement, it would be logical that these feelings do not provide for the production and regulation of quality. Finally, it has been noted that a parent is typically not able to easily change providers due to the emotional attachments of the child and family and the needs of the working parent(s). Evidence continues to support the fact that not-for-profit centres and/or publicly-operated centres are superior producers of quality ECEC.

\section{The Universal Child Care Benefit}

The Universal Child Care Benefit, originally called the Universal Choice in Childcare Benefit, is a good example of policy based on the traditional family rationale that has direct consequences on the childcare market and ultimately on ECEC policy. The Universal Child Care Benefit, now more commonly referred to as the UCCB, provides an income supplement of \$100 a month for 
every child under six years of age payable directly to parents (demand-side funding). The $\$ 100$ is taxed at the lower spouse's income thus most heavily benefitting families where there is a stay-athome parent who pays no income tax. Although the Conservative Party never overtly supported the market as the main approach to ECEC services, the proposal of the UCCB along with the cancellation of the ELCC Foundations program leaves the market as the main producer of ECEC in Canada rather than beginning to move away from the market towards an ECEC system.

\section{The "Choice" Discourse}

The parent "choice" in ECEC discourse was created to appeal to traditional family values to support the UCCB politically. For the purposes of this paper, discourse is understood to mean a way of talking about and representing the world through language. Discourses always have ideological foundations, even though they are seldom explicitly expressed in text (Fairclough, 2003).

The "choice" discourse is born out of the ideology of the traditional family as it values parents, usually the mother, as the preferred caregiver for children. When care cannot be provided by the parents themselves, it directly follows that parents should at least choose who, how, when, where and by whom their children receive care. Indeed, the "choice" discourse values enabling parent "choice" above all other aspects of ECEC - including quality, accessibility, and universality. The purpose of the "choice" discourse is to appeal to the ideology of traditional family values where parents are considered the preferred and superior caregivers for their children.

\section{The “Choice” Discourse in Theory}

In theory, the "choice" discourse has a strong appeal. It purports to allow parents who would like to be at home with their children this option while simultaneously purporting to allow parents who do not wish to or cannot stay home with their children the option of choosing who cares for their children in their absence. The "choice" discourse portrays the issue in a way that suggests government involvement in ECEC should not support any one child care option but rather should facilitate the prudent and responsible choices of Canadian parents, whatever they are. In theory, by viewing the childcare issue from the perspective of the "choice" discourse, parents" “choosing" their preferred options for their children's care is not only of the utmost importance, but is also achievable. 


\section{The "Choice" Discourse in Reality}

While the "choice" discourse appears to be empowering and liberating for parents in that they theoretically have the agency to enact their preferences for their children's care, it has little to no regard for the existence of suitable options that are a prerequisite for choice. In reality, a variety of quality ECEC options must be available to parents in order for their preference to become a choice. As has been established, quality, regulated childcare has always been an elusive option in Canada and was in a dismal state heading into the 2006 election. Although the ELCC Foundations Program had been announced, it was in its infancy; high quality, accessible and affordable ECEC was still a distant dream for the majority of Canadian families.

In order to promote the UCCB politically, the Conservatives used the "choice" discourse to appeal to traditional ideological values with little to no regard for the reality of the situation. The reality was that parents would actually have fewer quality ECEC options for their children as a result of the proposed policy changes. Cancelling the ELCC Foundations program and implementing the UCCB would continue to leave the market almost entirely responsible for the provision of ECEC services. From the perspective of families, $\$ 100$ a month would make no substantial difference in enabling ECEC choices: high quality care costs much more than this and the dollar amount is too limited to be a factor in a family's decision to have a parent stay home to provide child care. The main family type to benefit from the UCCB would be the traditional, nuclear family with one parent in the work force and another parent at home with the children. So although the "choice" discourse appears to be enticing and liberating, it is inherently misleading. The ideological foundations on which the "choice" discourse is built overshadowed the realities of the dismal state of ECEC in Canada.

\section{The ECEC Context in the 2006 Election}

Although the state of ECEC policy and services in Canada had been reported on before, the 2004 Starting Strong Canada Country Note Report published by the Organization for Economic Cooperation and Development (OECD) as part of a twenty country review put Canada's ECEC policy in an international perspective - a perspective Canadians had not had on the issue up until this point. Canada's ECEC policy was described as being in its "initial stages" (OECD, 2004, p.6) resulting in a "patchwork of uneconomic fragmented [ECEC] services" (OECD, 2004, p.6). It was further noted "there has been no significant expansion of the [ECEC] system in Canada 
over the past decade" (OECD, 2004, p.7). In Starting Strong II, the project's summary report that came out the year of the election, it was noted that Canada spent an embarrassing $0.25 \%$ of GDP on programs for $0-5$ year olds (OECD, 2006). This last figure is less than a quarter of what many European countries spend on programs for the same age group.

The OECD's Canada Background Report describes that ECEC spaces were available for only $15 \%$ of Canada's children age 0-6 (Doherty, Friendly \& Beach, 2003). In contrast, Sweden had spaces available for over $90 \%$ of children in the same age group (OECD, 2006). Parent fees averaged 50\% of the cost to maintain an ECEC space in Canada as compared to approximately $25 \%$ across most of Europe and 9\% in Sweden (Doherty, Lero, Goelman, LaGrange \& Tougas, 2000). While limited fee subsidies had been available for low-income families since the era of the Canada Assistance Plan (1966), in some provinces there were long waiting lists for these, while in others, the subsidy rarely covered the full cost of care.

At the same time, more mothers of children aged 0-5 were in the labour force than ever. 2007 statistics (which are based on the 2006 year) suggest that $69 \%$ of mothers of 0-2 year olds and $77 \%$ of mothers of 3-5 year olds were in the labour force (Beach, Friendly, Ferns, Prabhu \& Forer, 2008). Furthermore, the over-one million single mothers in Canada continued (and still continue) to face lower wages, non-typical hours and wage discrimination (Friendly \& Prentice, 2009). In families where there was a marriage, $83 \%$ of the time both spouses worked outside the home (Sauve, 2003). These numbers contribute to a strong demographic case for ECEC services based on an economic rationale.

In the late 1990's, Mustard and McCain's Early Years Study brought attention to the human capital angle on public investment in ECEC policy and services in Canada. It stated that: "there is encouraging evidence that good nutrition, nurturing and responsive caregiving in the first years of life, linked with good early child development programs, improve the outcomes for all children's learning, behavior, and physical and mental health throughout life" (McCain \& Mustard, 1999, p. 6). As such, the idea that it was in the long-term best interests of Canadians to invest in optimizing the populations' developmental potential became pertinent.

Although they had been in government for most of the previous three decades, the federal Liberal Party finally appeared to recognize and respond to the increasing evidence about Canada's poor ECEC policy. After becoming Prime Minister in 2004, the new leader of the 
Liberal Party, Paul Martin, committed to putting in place the funding and framework for a national childcare strategy. By December 2005, the Liberals had passed the ELCC Foundations program specifically allotting $\$ 5$ billion to increasing access to high quality ECEC programs. Bilateral agreements with the provinces were in the process of being signed as the 2006 election approached. In the 2006 election campaign, the Liberal party allotted an additional $\$ 6$ billion towards universally accessible, quality ECEC, making this the closest Canada had ever been to a national approach to ECEC.

The Conservatives had a different plan. In the 2006 election, their main proposition for ECEC policy was the UCCB, although they also promised $\$ 250$ million (annually) in tax credits to employers as an incentive to create childcare spaces in the private sphere. Instead of focusing on this contribution, the Conservative Party's attention was concentrated on the creation of the UCCB and the "choice" it would theoretically provide for parents.

\section{Socioeconomic and Political Context at Time of the Election}

It is important to point out that the 2006 election took place at a critical time for ECEC in Canada. With the ELCC foundations program, the Liberal government had accomplished more than any previous government in getting a national child care program off the ground; never had a federal government made a substantial and specific financial commitment to ECEC or gotten as far in developing a national ECEC program.

This election also took place during a time of "unparalleled prosperity and flexibility" according to the Canadian Centre for Policy Alternatives (CCPA, 2006, p.1). In the CCPA Alternative Federal Budget 2006, it was estimated that "the federal government will have budget surpluses of $\$ 74.8$ billion between 2006/07 - 2010/11" (CCPA, 2006, p.2). The recession of 2009 was not on the radar at the time of the election and Canada appeared to be in a strong enough financial position to offer social programs that could potentially improve the well-being of children and families.

On the federal political scene, Paul Martin had recently taken over as Prime Minister with Chrétien having stepped down at the end of 2003. Although the Liberals did win the June 2004 election, they were reduced to a minority government. Heading into the 2005-06 election, Martin was depicted by the Conservatives as being the most "hypocritical", 'indecisive", and "dishonest" of the political party leaders and his "unfavourable ratings exceeded his favourability scores" 
(The Strategic Counsel, 2005). Martin's time in office did little to revive his image; he was criticized by his political opponents for haphazardly trying to pursue too many priorities with not enough commitment to any one of them. Politically, the Liberal Party was in a difficult position heading into the 2006 election.

Stephen Harper and the Conservative party proposed a political platform that would "replace corruption with accountability" and provide "leadership for all" (Conservative Party Election Platform, 2006, p.2). The Conservatives placed heavy emphasis on providing "tax relief they [the people] can count on" (Government of Canada, Department of Finance, 2006). There was a general emphasis on reducing the role of government through lowering taxes - a model of government best characterized as a rightist neo-liberal welfare regime. Harper's campaign was effective and he won a minority government in the 2006 election.

\section{Academic Literature Pertaining to ECEC, the Media and the 2006 Election}

There has been limited scholarly literature published that directly addresses media coverage of ECEC in the 2005-2006 Canadian federal election. Albanese, Rauhala, Ferns, Johnston, Lam and Atack (2010) collected data from four daily newspapers that addressed childcare issues from the years 2000-2007. December 2005 and January 2006 are noted as being "clearly exceptional" (Albanese et al., 2010, p.825) months due to the large increase in the quantity of childcare coverage. These authors went on to note that, although the quantity of coverage increased in all four papers during these two months, the depth of the analysis of the childcare issue was lacking (Albanese et al., 2010). Rhinehart (2007) also noted this lack of critical analysis: "media coverage of the [child care] program was shallow and lacking in critical analysis" (Rhinehart, 2007, p. 8).

Rhinehart $(2007,2008)$ went on to provide an analysis of how childcare reporting during the election reflected a gender bias in mainstream media. She argued that because the media fails to promote female reporters and editors and provides a predominantly male editorial bias, childcare got an "easy ride" (Rhinehart, 2008, p.2) in newspapers during the 2006 election. Rhinehart's analysis does point out key words used in the press, such as "choice" and "institutionalization", but does not go into depth regarding how they may be indicative of ways of representing the world (i.e., discourse) and why or how these words may have influenced the thinking and actions of Canadians. 
Albanese et al. (in press) provides a more in-depth analysis of the data collected for the previously mentioned study. In this forthcoming publication, newspaper reports related to childcare 55 days before, during and after the 2005-2006 election campaign were explored in more detail. Albanese et al. (in press) explored two questions: 1) Does a paper's ideological stance come through in the reporting of the ECEC issue? 2) Who is quoted and when throughout the articles? Their findings indicate that politicians were quoted most often (as opposed to parents, child care workers, advocates, experts) and were the first or second speakers in all of the papers. There was not a significant difference in terms of sources quoted throughout the four papers, regardless of each paper's differing ideological stance.

In 2004, Theriault, a professor of sociology at the University of New Brunswick, published an analysis of The National Post's "The Nanny State" series on childcare. Theriault points out how this series framed the child care issue through a right-wing, Conservative lens. The National Post refers to a universal childcare system as "a massive top-down government-run program". The series concludes that Canadians (referred to as taxpayers throughout the series) should "say no to the nanny state". Theriault (2006) identifies the many fallacies the series reinforced, one being that funding given directly to parents is the optimal way of supporting quality childcare in Canada. Theriault also challenges incongruencies in the Conservative arguments against a national childcare system. For instance, while this series faults Quebec for its faltering quality in childcare, the same series also blasts Quebec's childcare workers for demanding unionization. Theriault (2006) points out the empirically supported fact that adequate working conditions and compensation are a key indicator of quality child care services; that it is simply unrealistic to suggest that paying child care workers wages hovering around the poverty line has no effect on the quality of services provided.

Theriault's analysis also points out the importance of framing- or how issues are presented to the public through mediated texts. He effectively identifies how ideology can often trump practicality when it comes to the public's understanding and appreciation of important social policy issues.

The current paper's analysis of texts produced during the 2006 election will focus more specifically on the textual and discourse processes that play a key role in framing an issue. The 
next section will describe how and why Fairclough's model of a critical discourse analysis is used to accomplish this goal. 


\section{Methodology}

This study employs a critical discourse analysis (CDA) methodological approach. There is no objectively 'right' or 'wrong' way of approaching a CDA and different theorists/authors have developed differing, although often complementary, strategies. This study is heavily influenced by the work of Fairclough (2003), though the criteria outlined below by van Dijk (1995) succinctly describe what CDA attempts to do:

- Addresses an important social issue.

- Takes a critical stance when addressing text and talk.

- Is multi-disciplinary (in this case bridging the fields of Early Childhood Education, Journalism, Psychology, Sociology and Political Science).

- Not only considers the semantics, word choices and grammar of communications, but also how and when text is organized and presented.

- Focuses on how relationships of power and dominance in society are created, maintained, and reproduced through text/talk.

- Attempts to address underlying ideologies in text/talk.

- Seeks to reveal what is "not immediately obvious in relations of discursively enacted dominance" (van Dijk, 1995, p.18)

Fairclough $(1995,2003)$ provides a systematic approach to CDA in the social sciences.

His method is based on the fundamental assumption that "language is an irreducible part of social life, dialectically interconnected with other elements of social life, so that social analysis and research always has to take account of language" (Fairclough, 2003, p.2). It is through language, often through the medium of text, that members of society exchange information, communicate, come to know their world and inform action. Becoming cognizant of and critically aware of the different elements of language in context is essential if we are to understand the world and effectively act upon it.

An underlying assumption of CDA is that authors are inherently subjective. Text, therefore, is always ripe with assumptions, ideologies, and grammatical and semantic tools (Fairclough, 2003). What is important is that consumers of text are aware of this subjectivity and 
do not fall into the trap of accepting information and the ideologies on which it is based as if it is a truly comprehensive and accurate reflection of the whole story.

Similarly, critical discourse analysis is inherently embedded in subjectivity, with authors conducting and reporting the research. Although much scientific research is dismissed without an adequate level of objectivity, CDA acknowledges that any analysis is always partial and based on the analyst's perception and understanding of the text (Fairclough, 2003). Instead of dismissing this research due to its lack of objectivity, CDA has the goal of raising "moral and political questions about contemporary society" (Fairclough, 2003, p.14). Ultimately, raising these questions, and engaging in a critical dialogue regarding social policy opens up the possibility of "change through critical understanding" (van Dijk, 1993, p.252).

\section{Key Concepts and Terms}

The definition of discourse, like many other words, is dependent on its context and author. Research using discourse analysis in the social sciences originally stems from the work of Foucault and post-structuralism. Foucault defined discourse as "a construction of social reality" or "form of knowledge" (Fairclough, 1995, p.18). Discourse as it is conceptualized in this study is heavily influenced by the work of Fairclough who builds on Foucault's definition of discourse while combining it with language studies. Fairclough views discourse as going beyond words on a page to be a "social practice" or "mode of action" that is not only shaped by social and historical factors, but also is "socially shaping" (Fairclough, 1995, p.55). Fairclough emphasizes that discourse is "an element of social life which is closely connected to other elements" (Fairclough, 2003, p.3). Foucault's influence is present in that how a discourse is constructed and portrayed is based on ideological assumptions, or ways of viewing the world. In a description of discourse, Fairclough (2003) states:

Discourses not only represent the world as it is (or rather is seen to be), they are also projective, imaginaries, representing possible worlds, which are different from the actual world, and tied in to projects to change the world in particular directions. (Fairclough, 2003, p. 124)

The key difference between Foucault and Fairclough's $(1995,2003)$ conceptualization of discourse is that Fairclough places the emphasis on the role of language in how we come to know our world, interact with it, are shaped by it and shape it. In particular, Fairclough has developed 
a method of critically analyzing texts to reveal discourse and the ideologies on which discourse is built.

This analysis will focus on one-way, mediated sources including newspaper articles, policy documents, and key political speeches (Fairclough, 2003). When texts are mediated, it suggests that they "make use of copying technologies which disseminate communication and preclude real interaction between 'sender' and 'receiver'" (Fairclough, 2003, p.219). Texts are one-way when the receiver of the text cannot or does not typically directly respond to the author. Citizens may have opportunities to access primary sources of information such as parliamentary debates, political interviews, and direct communication with politicians. However, given the sheer quantity of consumers, most information is disseminated through the media via print, television and the internet. Fairclough further states: "how we live in contemporary societies is heavily dependent upon mediated texts, which are also crucial in processes of governance" (Fairclough, 2003, p.219).

Gee (1996) uses the term dominant discourse to refer to discourse that leads to money, power and status. A dominant discourse is generally created and sustained by those with authority, such as professionals and politicians, in order to secure their own best interests and the desire to maintain or acquire money, power and/or status. Dominant discourses are easily accessed through the media and other public documents, publications and everyday conversations because they receive a great deal of attention and publicity. The effortless accessibility of dominant discourses, and occasional bombardment by such discourses, allows them to easily permeate throughout a population. During an election campaign, political parties have a vested interested in making their discourses dominant to ensure that the majority of citizens become aware of, accept, and vote for their party and the ideologies on which it is based.

With the vote, politicians achieve power. Power is defined by Fairclough as "the transformative capacity of human action...the capacity to intervene in a series of events so as to alter their course" (Fairclough, 203, p.41). It follows from this definition that those with power in society are those who have the ability to change, or not change, key components of society.

In a critical discourse analysis, it is important to further distinguish the concept of hegemony from power. Hegemony occurs when power is achieved by consensus rather than force (Fairclough, 2003). When individuals are persuaded to willingly buy into certain ideologies, 
often set out by those with power, their actions will reflect these ideologies and existing power structures are reinforced.

A key vehicle conveying ideologies are texts. Critical discourse analysis is a research methodology that explicitly attempts to break down the reinforcing cycle of power through recognizing hegemony and further examining the mediated texts in which it arises. Instead of providing answers as most empirical research attempts to do, CDA raises essential "moral and political questions about contemporary society" (Fairclough, 2003, p.14). These questions ultimately challenge consumers of the analysis to think more holistically, thoroughly and critically about the representation of the world through text. In a world where information is being projected at us constantly, through television, newspaper, the internet, and more recently, telephone and computer applications, the importance of critically examining these texts in order to create a more just and equitable society is paramount.

\section{Part I: The Dominance of the "Choice" Discourse}

\section{Data collection.}

The articles included in Part I were originally collected by Albanese et al (2010). Between 2001 and 2007, Albanese et al collected newspaper articles that referenced child care from four daily papers. These newspapers included The National Post, The Globe and Mail, The Toronto Star and The Ottawa Citizen. Using Proquest Newstand as a database, Albanese et al (2010) searched for articles that included "childcare" "child care", "daycare", and "day care" as key terms. Articles that contained these terms, but did not pertain to the childcare issue were disregarded. The articles in this study have been limited to The National Post and The Globe and Mail as these are Canada's two most prominent national newspapers. The timeframe chosen for this study is December 5, 2005 to January 23, 2006. These dates have been chosen for the following reasons:

1. December 2005 and January 2006 were noted as "clearly exceptional" (Albanese et al., 2010, p.825) months in childcare coverage due to a spike in the number of articles including the search terms listed above.

2. The election campaign took place between December 1, 2005 and January 23, 2006. December 5 was chosen as a starting date because this is the first day there was an article 
published in either paper that included the search terms. Election day was January 23, 2006 making it the end date of the articles.

Albanese et al (2010) found a total of 39 articles in The Globe and Mail and 60 articles in The National Post between December 1, 2005 and January 23, 2006 with the above-mentioned search terms. These are the articles that are included in this analysis. The title and author of the articles, section of the paper and links to each article were recorded in an excel spreadsheet and emailed to this author.

\section{Data Analysis}

A key element of Fairclough's analysis of discourse is the idea that discourses "are likely to be features of vocabulary - discourses 'word' or 'lexicalize' the world in particular ways" (Fairclough, 2003, p. 129). One of the key words of interest in this study is "choice" as it has been identified as the key element of the discourse being studied. Fairclough (2003) further emphasizes that not only words themselves, but also the location of words in relation to other words, can often be indicative of the presence of a discourse. In this case, searching for the word "choice" alone may not uncover the discourse of interest, but perhaps "choice" in a specific context will. As such, the word "parent", or derivative of this word, "Mom" and/or "Dad" must be present in relation to the word "choice" in order to confirm the presence of the "choice" discourse.

The words "beer and popcorn" have been included as indicators of the "choice" discourse. The prominence of this phrase arose from a comment that was made by Scott Reid, a key Liberal campaign staffer and the Liberal communications director, on December 11, 2005 during a CBC news panel discussion. Reid stated: "Don't give people 25 bucks a week to blow on beer and popcorn...Give them child-care spaces that work" (CBC News, 2005). This comment directly refers to the "choice" discourse in that it projects one possible way parents could spend the $\mathrm{UCCB}$ - on beer and popcorn. It also less directly points to the efficacy of the UCCB to deliver "choice". Thus, although beer and popcorn appear to have little to do with choice or ECEC, these words are in fact a coded version of the "choice" discourse as defined in this study.

Finally, the parent "choice" discourse will be defined as the dominant discourse if it appears in the majority of the texts. 
All 93 articles from both papers will undergo analysis in an attempt to answer the first research question:

1. How prevalent was the "choice" discourse in the 2005-2006 election? Was it dominant? In an attempt to answer this broad question, three more specific questions will be applied to the analysis. These are:

1. Do the words "parent" and "choice" appear together in the article?

2. Do the words "beer and popcorn" appear in the article?

3. Do these words or a combination of these words appear in more than half of the articles?

\section{Part II}

\section{Data Collection.}

The second portion of this study will use a Critical Discourse Analysis in an attempt to answer research questions 2 and 3:

Question 2: In addition to the "choice" discourse, what other discourses were used to support the proposed ECEC policies?

Question 3: How were textual and discourse processes used to control the dominant discourse(s)?

A CDA can be carried out in a number of different ways. The approach taken in this study is described below. Four of the newspaper articles from Part I are included in the CDA (as it was simply not feasible given the time constraints of this study to include all the articles). Instead, a thorough analysis of four articles, two from The Globe and two from The Post, will be carried out.

In addition to the newspaper articles, other texts including the ECEC policy platforms of the political parties, and relevant political speeches have been included. Original policy documents (i.e., campaign platforms) have been included because these are the documents devoted to relaying the messages of the parties themselves without the interference of secondary authors or reporters. The speeches are included as an example of mediated text that is more, although not entirely, bi-directional. As speeches are delivered in front of a live audience, there is 
direct contact between the sender and receiver of the spoken text. It is important to point out that, although the speeches are not specific to the timeframe of this study, they do clearly articulate where the leaders stood on the ECEC issue at the time of the election.

The following documents have been selected for an in-depth CDA:

1. Childcare platform of the Conservative party: Stand up for Canada 2006

2. Childcare platform of the Liberal party in the 2004 election

3. Childcare platform of the Liberal party in the 2006 election

4. Harper speech, April 2006

5. Martin speech, October 2004

6. The Globe and Mail Article 1: Whoa Baby! Chew on these child-care plans

7. The National Post Article 1: Tories tackle child care plan: Parents would decide how to spend $\$ 1,200$ per child

8. The Globe and Mail Article 2: Martin aid apologizes for child-care comment

9. The National Post Article 2: Scott Reid's Canada

\section{Justification for the documents chosen}

The portion of the 2006 Conservative election platform related to ECEC has been included because it is the original document where the Universal Child Care Benefit was introduced. This document was published by the Conservative party and provides explicit insight into this party's ideological stance and subsequent policy decisions. An analysis of this document should provide a thorough understanding of the proposed policy itself as well as insight into how the text and discourses were used to justify the policy to Canadians.

Similarly, the campaign platforms of the Liberal party in both the 2004 and 2006 that are relevant to ECEC will be reviewed. Both documents have been included because the Liberal party first introduced their ECEC policy in the 2004 election and then expanded on it in the 2006 election. These documents provide a thorough understanding of the policy at the time of the election and the proposed policy changes of the Liberal party. The analyses of these documents 
also provide insight into the dominant discourse(s) and textual processes used to justify the policy.

The newspaper articles included have been selected mainly because of their publication dates, but also because similar issues are covered. Two articles from the beginning, of the election have been chosen from The Globe and Mail and The National Post. The first articles in each paper were published on December 5, 2005, immediately following the Conservative party's proposal of the Universal Child Care Benefit. The second articles from the papers were published one day apart and address Scott Reid's "beer and popcorn" comment that received a great deal of media attention during the election.

Prime Minister Harper's speech of April 18 2006, after the Conservatives were in power but before the UCCB was passed in Parliament, has been included because it explicitly states where Mr. Harper stands on the issue. The UCCB had not yet taken effect and Mr. Harper was still essentially selling the Conservative policy to Canadians.

Mr. Martin's speech of October 6, 2004 in the House of Commons has been included as it represents Prime Minister Martin's position on ECEC policy. His position on ECEC remained consistent through to the 2006 election.

\section{Data Analysis}

The data analysis in this section will provide a CDA of the above-mentioned documents as conceptualized and operationalized by Fairclough (1995). The following diagram summarizes Fairclough's (1995) approach to CDA. 


\section{Figure 1: Fairclough's Model of Critical Discourse Analysis}

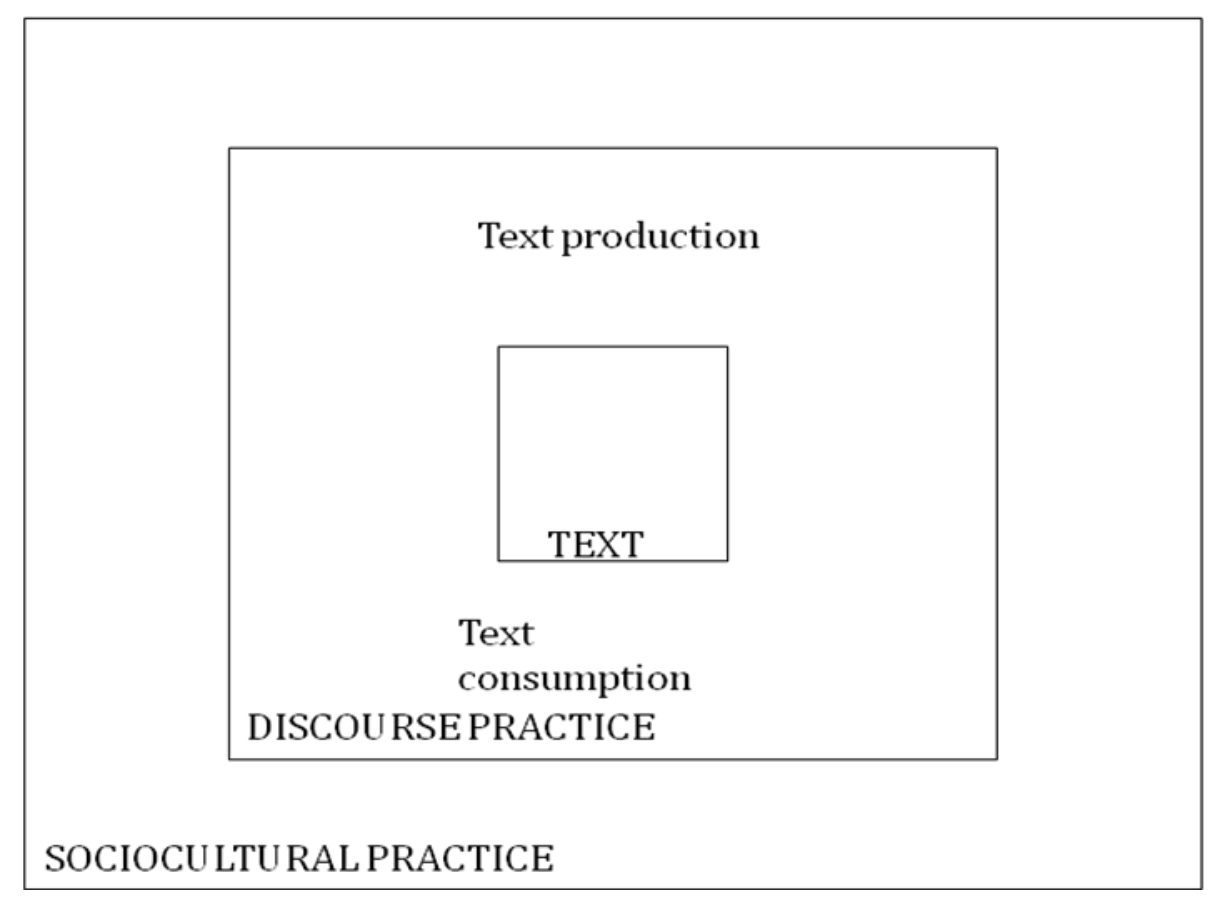

\section{Text}

Text examines the form and format of language. This includes an analysis of the words chosen, the structure of sentences, and the use of textual processes such as the use of metaphor and conversationalization. This part of the analysis will also attempt to uncover whether or not the text is oriented towards communicative and/or strategic action through the phrases and language used.

\section{Discourse Practice}

Discourse practice examines how text is produced, distributed and consumed. Fairclough focuses primarily on text production while acknowledging the importance of studying text consumption (Fairclough, 2003). Text consumption relies on a social cognitive method of understanding people's thinking and is thus not the focus of Fairclough's analysis. Instead, in this analysis, the concept of genre, discourse and style are emphasized. These are defined below:

- Genre: A way of acting and interacting linguistically. For example, the interview, lecture, and news report are different genres. Sometimes information is recontextualized between genres. This has the potential to alter the meaning of the original message and will, therefore, be one discourse process this study will attempt to uncover. 
- Discourse: A way of representing the world. An analysis of discourse involves identifying the ideological assumptions underlying the text, identifying which voices are and are not included.

- Style: Ways of being or identity in the text (i.e., an authoritative tone). The tone of the text will also be acknowledged and recognized when playing a key role in the analysis.

\section{Sociocultural practice}

Sociocultural practice examines the immediate and larger society and culture in which the communicative event is taking place. The larger sociocultural context has already been described above so this will not be a focus in the analysis itself. The sociocultural practice will, however, become relevant when interpreting the results.

\section{Questions}

The list of questions below was developed through a synthesis of Fairclough's (2003) guide to carrying out CDA and a preliminary review of the data. These questions are by no means exhaustive, but instead provide a guideline for addressing each level of the analysis. Including such a list contributes to increased objectivity and intra-rater reliability. 
Table 1: Questions for CDA

\begin{tabular}{|c|c|c|}
\hline Text & Discourse & Sociocultural \\
\hline $\begin{array}{l}\text { - Is } \\
\text { conversationalization* } \\
\text { present? }\end{array}$ & $\begin{array}{l}\text { What is/are the } \\
\text { dominant discourse(s)? }\end{array}$ & $\begin{array}{l}\text { What is the social } \\
\text { setting the text is } \\
\text { taking place in? }\end{array}$ \\
\hline $\begin{array}{l}\text { What speech function } \\
\text { does the document } \\
\text { primarily consist of? } \\
\text { (i.e., demand, offer, } \\
\text { question, statement) }\end{array}$ & $\begin{array}{l}\text { What are some of the } \\
\text { existential, } \\
\text { propositional, and } \\
\text { value assumptions } \\
\text { made throughout the } \\
\text { text? }\end{array}$ & $\begin{array}{l}\text { What is the political } \\
\text { setting the text is } \\
\text { taking place in? }\end{array}$ \\
\hline $\begin{array}{l}\text { Are statements realis, } \\
\text { irrealis, or } \\
\text { evaluations? }\end{array}$ & $\begin{array}{l}\text { - Does } \\
\text { recontextualization of } \\
\text { information take place? }\end{array}$ & \\
\hline $\begin{array}{l}\text { Is the text oriented to } \\
\text { strategic action or } \\
\text { communicative action? } \\
\text { How? }\end{array}$ & $\begin{array}{l}\text { What is the style/tone } \\
\text { of the text? } \\
\text { What degree of } \\
\text { intertextuality is there? }\end{array}$ & \\
\hline $\begin{array}{l}\text { How is the text } \\
\text { structured so as to } \\
\text { legitimize dominant } \\
\text { discourse(s)? }\end{array}$ & & \\
\hline $\begin{array}{l}\text { Is there evidence of } \\
\text { nominalization? }\end{array}$ & & \\
\hline
\end{tabular}

*Please refer to Appendix A for definition of italicized words. 


\section{Results}

\section{Part I}

The analysis of all the newspaper articles from The National Post and The Globe and Mail found that the majority of the articles contained the "choice" discourse. Approximately 58\% (22/38) of the articles in The Globe and Mail and 58\% (35/60) of the articles in The National Post contained the "choice" discourse as defined by the above search criteria. The N/A category was necessary because several articles that met the search criteria in the initial study of Albanese et al (2010) (i.e. the article contained the word "daycare") but were not applicable to this analysis because they did not refer to the ECEC policy proposals during the election. For example, one article reported a recent fire in a childcare centre while another addressed criminal activity taking place near a childcare centre. Omitting the N/A articles, the "choice" discourse was apparent in $71 \%$ (22/31) of articles in The Globe and Mail and 65\% (35/54) of articles in The National Post. These numbers indicate that the "choice" discourse was present in $67 \%(57 / 85)$ of the relevant articles indicating its role as a dominant discourse in newspapers throughout the election.

Table 2: Presence of the "Choice" Discourse

\begin{tabular}{|c|c|c|}
\hline Presence of "choice” discourse & The Globe and Mail & The National Post \\
\hline Yes & 22 & 35 \\
\hline No & 9 & 54 \\
\hline TOTAL RELEVANT & 31 & 6 \\
\hline N/A & 7 & $\mathbf{6 0}$ \\
\hline
\end{tabular}

When analyzing many of the articles it was not necessary to look beyond the title to identify the "choice" discourse. For example, titles of articles in The National Post included "Give Parents the Power of Choice", "A Question of Choice", "The Tory Plan is Beer and Popcorn Money", "Say You Had \$1200 to Spend on Beer and Popcorn”, and finally, “Above All: Choice". In the Globe and Mail titles were less extreme. They included: "Harper's Prescription for Choice in Childcare", and "Popcorn, Beer and Childcare". When getting beyond the titles of 
articles, phrases indicative of the "choice" discourse were readily apparent and often repeated. For example, the sentiment that parents should be able to spend their tax dollars how they "choose", "see fit" and/or "however they want" was commonly stated. The underlying traditional family ideological lens used to support the "choice" discourse was promoted through another repeated quote from Mr. Harper in The National Post: "there are already millions of child care experts in this country and their names are mom and dad". Furthermore, there were attempts in the texts to scare citizens when the "choice" discourse was taken one step further to suggest that parents would be "forced [to place their children] into regulated care". These are only a few examples of the many statements contributing to the dominance of the "choice" discourse.

Although initially not part of the methodology, it was interesting to note the frequency with which the "choice" discourse was explicitly challenged in the newspaper articles. Relatively few articles presented a counter-balancing view or acknowledged weaknesses in the "choice" discourse. The "choice" discourse was challenged in 5 of 31 relevant articles in The Globe (16\%) and 5 of 54 relevant articles in The Post (9\%). An example of text challenging the "choice" discourse includes statements such as: "It [the UCCB] is a tidy little Christmas present for an underappreciated segment of voters, but it will do little to assist anyone's choice" and "I think only people who need government cheques should get government cheques". Given the extremely limited capacity of the UCCB to provide a substantial increase in the choices of Canadian parents related to ECEC, it is interesting to note the relatively few number of challenges to the "choice" discourse.

\section{Part II}

The Globe and Mail Article 1: Whoa baby - Chew on These Child Care Plans.

\section{Text analysis.}

This article was published December 6, 2005 - the day after the Conservative platform was released. The article essentially sets up a comparison between the ELCC Foundations program and the new Universal Child Care Benefit. A short introduction highlights the difference between the two ECEC policy proposals. A description of the Conservative and Liberal plans, statements regarding the "philosophy" of the plans and quotes from party leaders that "attack" the opposing party's plan follow. 
Overall, this article has a conversationalist tone as is evident from the title: "Whoa Baby! Chew on these Child-Care Plans". Such a title creates an informal, catchy and colloquial use of words to get the reader's attention and elicits interest with the exclamation mark. There is evidence of both strategic and communicative action, though the former is arguably more prominent. The form of the article is communicative in that it appears to share unbiased information from both parties. There is a neutral introduction, followed by a portion of the article dedicated to a discussion of the Conservative ECEC platform and a portion of the article dedicated to the Liberal ECEC platform.

Upon analysis, the content of the text reveals language that more positively frames the Conservative platform and is indicative of strategic action. The "philosophy" that is reported to underlie the Conservative platform reads: “...families need choice in terms of daycare, and that families in which one parent stays at home with the kids deserve help too". The next sentence reiterates; "the Conservatives would help all kinds of families, and not just those that fit the government mold of institutionalized daycare". It is said that the money given to childcare could be spent "however parents wish". The article goes on to use realis, or factual, statements to describe the details of the UCCB and \$250 million in grants to employers to create childcare spaces. It also states that the total investment in the UCCB over five years would be $\$ 10.9$ billion. This section concludes with a quote from Harper: "Some want to build a national system of institutional daycare. I call that the Henry Ford model of child care. You can choose any colour you like as long as it's black. You can choose any child care you like, as long as it's nine-to-five, institutional care".

Several textual processes become apparent in the above-mentioned quotations. First and foremost is the process of nominalization. "Choice" has been nominalized in the first quotation in the typical manner of the "choice" discourse. It becomes a metaphor for freedom while obfuscating the options parents have to choose from. Perhaps more importantly in this article is the nominalization of institutionalization. The word "institionalization" is used to represent care that takes place in any regulated setting outside of the home. This word has inherently negative connotations and in this context it is used to elicit images of a cold, sterile, structured and rigid environment. The use of the name "Henry Ford" is not only colloquial, but furthers the image of mass produced, one-size-fits-all institutional childcare, like the always-black Model T that Henry Ford pioneered. 
The portion of the article dedicated to the Liberal platform follows these negative images of childcare that take place outside of the home. It begins with the same form as the Conservative portion of the article, stating the philosophy of the Liberal plan. It reads: "The Liberals have promised to help deliver a national network of regulated child-care spaces with the provinces". Interestingly, this statement is actually realis and not philosophical or ideological. The next statement does touch on ideology when it says: "The goal is to create the kind of early-learning programs that experts say are beneficial to the long-term development of children". The article goes on to mention the QUAD principles, 625,000 new spaces, and the Liberal government's intent to invest money directly into "daycare". Because the policy platform of the Liberals had not been released at this point, the total amount of money being reported to be spent on this initiative amounted to $\$ 5$ billion over five years - less than half of what the Conservatives were proposing for the UCCB.

Interestingly, the "attack" on the Conservative plan included in this article questions Harper's plan to spend the $\$ 250$ million in corporate grants to create childcare spaces. It states, "Unless Harper is triple-bunking the toddlers, he has exaggerated the number of spaces to be created by $400 \%$ ". It is interesting to note that that this aspect of the Conservative platform is questioned, given that the emphasis of the Conservative policy was on the UCCB. Furthermore, the earlier portion of this article that addresses the Conservative policy actually demonizes the "institutional" childcare for which it has committed \$250 million.

\section{Discourse Analysis}

The dominant discourse in this article is the "choice" discourse. There is emphasis on the idea that all families' choices should be optimized and that the best way to do this is to give all parents money to spend how they choose. More specifically, families in which there is a stay-at- home parent are referenced twice in the section of the article that addresses the Conservative policy. The voice of the traditional family, especially families with a stay-athome parent, generally the mother, is most strongly articulated in the text. Again, the ideological assumption that the care and education of young children is a private, family responsibility comes through as the voices of working parents, children, child care workers, child care experts and researchers are absent. 
There is one exception to this in the introductory paragraph of the text. Martha Friendly, a key childcare researcher in Canada is quoted as saying: "The two visions are diametrically opposed, they are really, really different. The details of the Harper program are pretty clear because they're pretty simple. The details of what happens next [with the Liberal plan] will be very important". This statement does not directly endorse or support either policy, but it does attest to the significant differences between the plans. What is interesting is the statement that follows this quote: "On this issue, at least, Canadians will have a clear choice between the two major parties in the election". Given the significant presence of the word "choice" in the ECEC policy debate, and the positive way it is again equated with freedom in this context, this quote brings to mind the importance of "choice". The difference between the use of the word "choice" here and its use in the "choice" discourse is that here two existing options are pointed out: the Liberal and Conservative policies. In essence, however, Friendly's quote could be interpreted by readers as an endorsement of the "choice" discourse based on how this quote was juxtaposed between subsequent statements in the article.

The main tactic used to legitimize the "choice" discourse in the article is its appeal to moral values. In addition to the moral value of the sanctity of the nuclear family and traditional roles of men and women, there is also an appeal to the values of equality and universality. The idea that "all families" would benefit under the Conservative plan, as opposed to the few families that would benefit under the Liberal plan, comes through. This assumption is not discussed or related to demographics, statistics or any kind of objective data. Instead, there is the suggestion that parents with a stay-at-home parent have been excluded from the early learning and child care debate and only now, with the Harper government's proposal of the UCCB, are being recognized.

The human capital discourse is very briefly touched upon in the portion of the article dedicated to the Liberal plan. The benefit of childcare to the "long-term development of children" is referred to when prefacing the QUAD principles.

\section{The National Post Article 1: Tories Tackle Child Care}

\section{Text Analysis}

This article was also published December 6, 2005 - the day after the Conservative ECEC policy was released. The article begins by reporting the ECEC policy announcement made by the Conservative party the day prior through the use of direct quotations. Following this, the article 
reports the Liberal response to the Conservative policy announcement - again with the use of direct quotations. Contextual information describing the initiatives the Liberal government had undertaken in ECEC prior to the election follows. The agreements-in-principle signed with the provinces and accompanying \$5 billion over 5 years that was dedicated to the establishment of a national ECEC system are reviewed. This document also contains a direct quotation from the leader of the NDP, the current Liberal Social Development Minister and the Conservative Party's Social Development Critic. The inclusion of several different voices and viewpoints highlights the dialogical nature of this text. The final two quotations of the article, from the Conservative Critic, Rona Ambrose, leave the reader with a Conservative bias: "We trust parents to make the choices that are best for their families...the Liberals don't trust Canadians with their own money, particularly in this account."

One textual technique this article uses is the sandwiching of irrealis clauses between realis clauses. Realis statements are factual and cannot be disagreed with. Irrealis statements are predictive, but often erroneously accepted as fact. By sandwiching irrealis statements between the realis statements, the irrealis statements are more likely to be accepted rather than challenged or critically examined. For example a portion of this text reads:

Families with children younger than six would receive a $\$ 100$ payment each month to use how they see fit (realis)...contrasting the proposal with the Liberal plans to create a national child-care system - something he characterizes as a restrictive 'child-care bureaucracy' (irrealis).

The first part of this sentence is factual, stating how the policy works. The second part of this sentence is predictive when it uses the term "child-care bureaucracy". Since the reader has already agreed with the first statement, it is more likely that he/she will also accept with the information in the second statement.

Later in the article, this sandwiching appears again when Mr. Harper says:

Of course it costs more than $\$ 1200$ a year to raise a child" (realis) ...but this will help parents with the choices they have to make (irrealis) ...it's hard enough to be a parent (realis)...the government should support your choices, not limit them (irrealis).

In both of these examples, the reader is brought on board with a statement of fact, and then given information that could be questioned. Challenging the irrealis statements is less likely since the reader has agreed with the earlier statement, and so on. The result of this process is that 
the reader comes to understand that: a) the Conservative plan provides access to more choices for parents, and b) the current Liberal government is limiting choices through creating childcare spaces. Both of these premises are highly questionable.

\section{Discourse Analysis}

The "choice" discourse is dominant in this article. It is the first discourse introduced, explored throughout the bulk of the article and supported in the closing quotation. Other discourses are raised in the body of the article, but do not have the same salience. For example, the first direct quote in the article states, "the government should support your choices, not limit them". The last direct quotation in the article, and concluding statement, reads: "We trust parents to make the choices that are best for the families...the Liberals don't trust Canadians with their own money, particularly in this account". The underlying value assumptions of this discourse point again to the importance of traditional family values in that parents bear the burden of securing their children's well-being and opportunity with intervention from the state being limited to money-inhand.

The word "choice" is also used as it was in the previous article - to point out the clear difference between the two parties' ECEC proposals. The first Martin quotation included in the article; "Canadians will face a stark choice when they head to the polls", arguably serves as a reminder to consumers that "choice" is ideal, democratic, and a fundamental prerequisite to freedom. This quote comes shortly after Harper's statement; "the government should support your choices, not limit them". These two uses of the word "choice" - in close succession and all in reference to ECEC policy in some capacity - have fundamentally different meanings. The Conservatives are heavily relying on "choice" as a metaphor for freedom regardless of its actual direct connection with freedom of choice in childcare. When the word is then used in a context where it genuinely does refer to the creation of options (choice between the two ECEC policy proposals) one could argue that it reinforces the metaphor of the Conservative policy. It reminds Canadians of the importance of choice and freedom without a critical examination of how the UCCB is able, or not able, to provide for this choice.

As was mentioned above, there is evidence of dialogicity in this text given the voices of Liberal and NDP politicians are included through attacks on the opposing party's ECEC policy proposals. For example, Mr. Martin states: “Mr. Harper has said he doesn't believe in subsidized 
child care and early development. Well, I do". Similarly, Mr. Layton is quoted as saying: "Mr. Harper's got it all wrong". Although these voices are included, there is very little explanation as to why Harper has "it all wrong” or what lead Martin to conclude that Harper doesn't believe in subsidized childcare. A thorough and informed explanation of the reasoning behind these quotations would have lead to greater dialogicity of the text and a more in-depth discussion of the different discourses on which these statements are based.

On the other hand, there is information included that supports the "choice" discourse. For example, it is stated " $23 \%$ of parents choose to put their children into 'institutional' daycare". This is a prime example of information being recontextualized. Although it is unclear where this statistic was taken from, it is likely a result of a survey published by The Vanier Institute of the Family in 2003. When parents were asked where and by whom their children would be cared for in an ideal world, over $80 \%$ of parents responded that they would like to care for their children themselves in the home (Sauve, 2003). However, it is vitally important to point out that the question was phrased such that social, practical and economic restraints were removed from the equation. The Vanier Institute's president actually responded to the misrepresentation of their data by the media and politicians through an open letter. For most Canadians, these constraints are pivotal in the actual options from which they chose childcare.

\section{The Globe and Mail Article 2: Martin Aide Apologizes for Child Care Comment}

\section{Text Analysis}

This article was published on December 11, 2005 - the day after Scott Reid made the beer and popcorn comment. The article summarizes the series of events that took place following Reid's comment. Quotations are included from Reid, another Liberal strategist who publicly agreed with Reid's statements and Paul Martin. There are no direct quotations from Conservative strategists or politicians and/or others who were offended by Reid's comment. Instead, this article attempts to address the strong presence these voices had elsewhere in the campaign.

Conversationalization plays a key role in the textual analysis of this article. First and foremost, the original comment of Reid's that this article focuses on is a prime example of conversationalization. Reid said: “Don’t give people \$25 bucks a week to blow on beer and popcorn. Give them child-care spaces that work". The use of the words "blow, "beer" and "popcorn" translate key policy issues into everyday, colloquial language. In doing this, meaning 
is obfuscated. All three of these words imply an irresponsible use of money by parents. The other interpretation of Reid's words - that $\$ 25$ a week is simply not enough money to make a difference to a parent's choice in childcare, is lost with the use of the words chosen in the original quote.

It becomes apparent in the first sentence of this article that the unintentional meaning of Reid's phrase was accepted as fact by the author of this article. The opening statement, which is presented as a realis statement, reads: “One of Paul Martin's top aides apologized to Canadian parents yesterday after saying on national television that they would buy popcorn and beer with the money the Conservatives are offering for child care". This sentence both paraphrases and recontextualizes the original comment. The omission of the clauses "working families need care" and "give them child-care spaces that work" as well as the addition of the word "would" reinforces the idea that the Liberal government believes parents are irresponsible and that the Liberals believe they know best. This sentence comes before the direct quote from Reid, which puts the quotation back into its original context, so the consumer has a misunderstanding of Reid's message before reading his words.

The article goes on to quote Reid's apology and admission that "it was a dumb way to make my point". He attempts to clarify what he intended to say when he states: "I apologize because, obviously no responsible parent would make that choice. The point remains that Mr. Harper offers a tax cut not a child-care plan". This quote is placed directly in the middle of the article - after the opening sentence that has already reported Reid saying that parents would make the choice to spend childcare money on beer and popcorn. This gives the impression that Reid had revoked his earlier statement, when in reality, he was simply apologizing for the misinterpretation of the message - not the message itself.

Later, the article describes how John Duffy, another Liberal strategist, stood behind Reid's comments before the official apology. The way this information is presented makes it appear that Duffy supports the misinterpreted meaning of Reid's quote. Duffy's words, that "there is nothing to stop people from spending it on beer or popcorn or a coat or a car or anything" further damage the Liberals by continuing to use conversationalization rather than thoroughly explaining the intended meaning of the message - that with the UCCB, the money does not necessarily go to childcare. Reid or Duffy could have made their point more effectively 
by citing other, more "responsible" ways that parents could have spent the UCCB - education savings, music lessons, sports, etc... By using "beer", "popcorn”, "a car", and "a coat" their underlying point was completely overlooked. This article is a prime example of how the words chosen and language used is of pivotal importance in effective communication. Although colloquial language may be appropriate in informal, everyday conversation with individuals who are familiar with each other, it is an entirely different thing to use such language in formal, public, mass produced texts.

The article concludes with a quote from Paul Martin, who was essentially doing damage control. Martin's attempt to address the misinterpretation of Reid's comment is relayed when he says: "parents are concerned about their children and are going to use that money in a way that, I'm sure, is responsible...But it will only help pay for child care one or two days a week. What about the other days of the month?" This quote gets back to the truthful and intended meaning behind Reid's statement, but it was arguably too late for those who took Reid's comment at face value.

Overall, this text has elements of both strategic and communicative action. The article provided a venue for the Liberals to clarify what was meant by the comment. Direct quotes from Reid, Duffy and Martin give a voice to the Liberals who were being attacked for, what were perceived to be, thoughtless and insulting comments about parents. At the same time, the textual processes and word choices at times reinforce the misinterpreted meaning of the "beer and popcorn" quote.

\section{Discourse Analysis}

The "choice" discourse is dominant in this text. "Beer and popcorn" represents the choice that parents could make with the UCCB. The original comment was attempting to poke holes at the "choice" discourse in that it was intended to challenge the efficacy of the UCCB to provide parents with choices in childcare. In clarifying Reid's message, both Reid and Martin point out the limitation of $\$ 100$ a month in providing choices in childcare. The human and economic capital discourses - which the Liberals heavily relied on in their platform, do not come up at all. These discourses are apparent in the first clause of Reid's original quote when he says "they [parents] need care that is regulated, safe and secure and that's what we're building here". The reasons why these three elements of childcare are important, which are based on the human 
capital and economic rationales, are left out of the discussion entirely. Instead, the focus of the article is on clarifying a comment that attempted (and failed) to address an objective weakness in the Conservative ECEC policy.

Although other rationales and discourses are not put forth, the underlying ideologies of the "choice" discourse are challenged. Through the inclusion of the quotes from Reid, Duffy and Martin, the assumption that childcare is a private responsibility with little government intervention is questioned. While Reid was attempting to point out the important role government can play in providing childcare spaces, he was ineffective in his presentation and unintentionally both undermined Canadian parents and a national ECEC program.

\section{The National Post Article 2: Scott Reid's Canada}

\section{Text Analysis}

This article was published December 13, 2005 as an editorial in The National Post. It is heavily oriented toward strategic action as it attacks not only Reid and his comment, but also extends this attack to other social policies and the Liberal party more generally. Reid's quote is recontextualized and grossly misinterpreted by the author. As in the former Globe article, this article takes Reid's quote out of the television genre in which it was first spoken, omits the clause before and after the comment, and rewords the comment itself. It reports that: "if child-care money were under the control of parents themselves, they [parents] would simply 'blow it on beer and popcorn'". The 'blow it on beer and popcorn' is put in direct quotes while the information that came before these direct quotes was changed. This recontextualization of information leads the reader to believe that Reid did indeed challenge the efficacy of parents when in fact the communicative intent behind the comment was fundamentally different. In this case, a colloquial comment recontextualized spelled political disaster for the Liberals.

This article also addresses the idea that Reid's comment was a "gaffe". Other reporters and media outlets at the time had suggested Reid's 'beer and popcorn' comment was a mere slip of the tongue. This author instead suggests that the comment was a "rare look through the Liberals' glasses - a chance to see how they view Canadians, and why they favour such a paternalistic mode of government". These irrealis statements continue when the author suggests: "Paul Martin insists on only one option [in child-care]: a top-down network of state-approved daycare centres" and that the Liberals believe that "bureaucrats know better than parents what is 
best for children". All these statements have an accusatory, matter-of-fact tone when, in fact, there is nothing to support these claims. Indeed, Reid's comment is manipulated to enforce the obvious agenda of this author - to demonize the Liberal party.

In interpreting Reid's comments literally, this author uses sarcasm to reinforce the perceived lack of trust on the part of the Liberal party in regards to Canadian parents. After falsely citing statistics stating that only $13 \%$ of Canadian families favour "institutional daycare" as the primary form of care, the author facetiously suggests that the other " $87 \%$ of Canadians are making the 'wrong' choice by the Liberals' lights - no doubt thanks to the inebriating effect of the booze they are quaffing with their children's lunch money". This comment takes Reid's already out-of-context comment a step further to imply an even higher level of irresponsibility: immoral and dangerous behavior on the part of Canadian parents.

\section{Discourse analysis}

The "choice" discourse and the ideologies on which it is based heavily permeate this text. The idea that government involvement in the social welfare of its citizens limits choice rather than creates choice is supported in the text when referring to Canada's health care system. The author expresses the idea that, "On health care, the Liberals refuse to permit personal choice - insisting that Canadians either sign on to their health monopoly or flee the country to get more timely care in the United States". In only five paragraphs of text, the author accuses the Liberals of creating a "culture of dependency", having a "condescending theory of government", and operating a "paternalist mode of government". Clearly this author feels strongly that childcare, and the social welfare of citizens more generally, should be left as a private responsibility where individual success in the market dominates.

Other discourses, such as the human capital, are completely absent from this text. The Conservative voice dominates with opposing viewpoints left out. Different interpretations of Reid's comment are not explored at all. Instead, Reid's quote is used as evidence that the Liberal government does not trust its citizens and a Conservative government does. As a consequence of "trusting" citizens, the Conservatives appear to promise choice through individual responsibility, hard work and success in the market.

\section{The Conservative Party Platform}




\section{Textual analysis}

This document has a conversational tone as is evident by the use of colloquial language throughout. For example, the platform begins with an attack on the reigning Liberal government stating: "The Liberals must be held accountable for the stolen money; accountable for the broken trust; and accountable for all that they failed to accomplish because of this government's total preoccupation with scandal and damage control". The words "stolen", "scandal", "total preoccupation" and "damage control" can all be considered colloquial word choices in the context of an official policy document. Later in the document, the phrases "one-size-fits-all" and "massive childcare bureaucracy" are used to describe the Liberal plan for a national ECEC strategy. Again, these words and phrases have an accusatory, conversational tone that result in the oversimplification of a complex issue.

This document also contains several irrealis statements. It predicts that the aforementioned "massive childcare bureaucracy" will benefit only "a small percentage of Canadians". Much comparative policy analysis in the field of ECEC suggests otherwise (OECD, $2004,2006)$. This research is completely unaddressed in the document.

The Conservative platform also contains many statements that appear to be realis when they are actually highly subjective statements. For example, it states: "The Liberals and NDP believe that the only answer to expanding childcare in Canada is their one-size-fits-all plan to build a massive childcare bureaucracy" and later "only the Conservatives believe in freedom of choice in child care". Both of these statements are presented as if objectively true, however, they are overgeneralizations and overly simplistic. To say that the Liberal and New Democratic Parties do not believe in freedom of choice would be considered not only erroneous but also offensive to many.

Evidence of nominalization is also plentiful. "Choice" has been nominalized in the typical manner of the "choice" discourse. It becomes a metaphor for freedom while obfuscating the options that parents have to choose from. The subtitle of the section, "A New Choice in Child Care Allowance" implies that this allowance will provide a new level of freedom for parents struggling to find and afford ECEC.

Such an approach is indicative of a text oriented to strategic action rather than communicative action. In fact, the text explicitly states what is "best" when it says: "the best role 
for government is to let parents choose what's best for their children”. There is actually no acknowledgement or mention of other viewpoints - many of which are based on strong rationales in support of other ECEC policies. Instead of addressing opposing viewpoints or different ways of doing things, this document has the sole intention of selling the UCCB. The general message, although phrased less harshly in the document, could read: "Do you believe in freedom of choice in childcare? Vote for us and you will be able to choose whatever childcare options you wish!" Rather than attempting to genuinely communicate a strong rationale for the policy the Conservatives were proposing, the document uses colloquial language and oversimplified text and employs nominalization to sell its policy.

\section{Discourse analysis}

The "choice" discourse is dominant in this document as evidenced by the frequent repetition of the word "choice" (seven times in two paragraphs) as well as the underlying ideological assumptions that permeate the text. Some of these value assumptions include:

- The well-being of children is a private, family responsibility.

- "Choice" for parents regarding the care of their children is a priority over any other aspect of childcare.

- Any policy other than giving parents money-in-hand infringes on individual freedom and decision making.

The discourse is presented from the point of view that cash for parents equals choice in childcare, and choice in childcare equals freedom for parents. The voice of the traditional family comes through in this text. Stay-at-home parents and informal care networks (neighbours and relatives) are explicitly supported. When discussing the care options that the Conservatives assume to be available they include: "formal child care, informal care through neighbours or relatives, or a parent staying at home". The authors of this policy suggest that "formal care options" are available to those who want it and that $\$ 1200$ a year will make the difference in the ability to access such care. The absence of key voices such as single parent families, families of low SES, childcare experts/advocates, modest income families who can't find or afford child care, and dual-income families allows these assumptions to go unchallenged. 
Instead of logically breaking down the issue in terms of how the proposed policy will or will not make a difference in the choices Canadian parents will have regarding ECEC, an appeal to traditional moral family values as well as the abstract idea of freedom are relied upon to legitimize the "choice" discourse. The belief that ideal childcare is provided by the family (typically the mother) is supported with the policy provision that the spouse with the lower income receive the tax benefit. The result of this is that families with a stay-at-home parent receive the most money. Furthermore, the strong knower to non-knower tone as evidenced in overly simplistic, predictive statement after overly simplistic, predictive statement (i.e., "only the Conservatives believe in choice in child care") leaves little room for objection or question. All of these textual and discourse processes combine to sell the "choice" discourse. The Conservatives are clearly aware that the idea that choice is freedom will have massive appeal in a democratic country.

\section{Liberal Party Platform 2004}

\section{Text analysis}

There is less evidence of conversationalization in this document than in the Conservative platform. Formal terms such as "early learning and child care system" are used instead of colloquial terms like "massive childcare bureaucracy" or even "daycare". The part of the document dedicated to childcare is significantly longer in that it contains three pages rather than three paragraphs of text. Empirical research and evidence from other countries is referred to in support of the proposed policy. Although the document does not cite specific research, it does say "Studies conducted in Canada and throughout the world conclude that good child care and early learning contribute immensely to the healthy growth of children". The greater length of the document and reference to research as well as past policy initiatives indicate an attempt at communicative action as opposed to strategic action only. On the other hand, phrases such as "Canada has not done enough" and the final sentence, "the time has come to do more" indicate strategic action. This document is best characterized as having elements of both communicative and strategic action.

Some realis statements are made in the text to support the policy. For example, it says: "both parents want to, and often need to participate more fully in the paid labour force". 
Other statements are presented as realis, but are actually irrealis. For example, it says "future achievement is set in early childhood", "investment in childcare and early learning is the key to success in the $21^{\text {st }}$ century economy" and "it [quality ECEC] gives kids the best possible start in life". Whereas the first of these quotes indicates an economic discourse, the majority of the document draws on the human capital discourse. This discourse is based on the human capital rationale, which views quality ECEC as a necessary prerequisite to a smart and productive population.

\section{Discourse analysis}

It becomes evident that the human capital discourse is dominant in this document given its heavy reliance on the idea that quality ECEC is a "smart investment" and the "best investment" for Canada. Key assumptions that underly this discourse and permeate the text include

- Quality ECEC experience is necessary for optimal development of children.

- Investing tax dollars into ECEC is economically prudent in the short and long-term.

- Quality ECEC services can complement parenting.

The main tactic used to justify the use of the human capital discourse is rationalization. Rationalization legitimizes the dominant discourse by linking it to the utility of institutionalized action (Fairclough, 2003). The institutionalized action in this case would be the development of a national ECEC system. The utility of this action, or agreed-upon beneficial outcome to the country, is the provision for the optimal development of children and an increase in the potential economic value of future generations.

It is important to note that the QUAD principles, which stand for Quality, Universal, Accessible, and Developmental, are first introduced in this document. Interestingly, the first three elements are not emphasized in the text. There is one passing reference to quality, universality and accessibility when referring to "progressive systems commonplace through Europe". However, it is mainly the educational component of these systems that is elaborated on in the text.

It is interesting to note that the 2004 Liberal Policy platform also incorporates the word "choice" into the text, though in a different capacity than the 2006 Conservative platform. It says, "Government is about making choices - choices about how to devote finite resources so that they 
accomplish the most good for the people". This quote does not nominalize "choice" as it explicitly addresses the fact that finite resources limit choices. Instead, it conceptualizes choice as a collective choice rather than individual choice. The collective choice referred to here considers what is best for the citizens of society rather than the individual consumer. Collective choice values democracy, equity and public responsibility for goods and services considered central to the well-being of citizens (Moss, 2008).

The closing statement of the policy draws again on the human capital discourse: "The time has come to do more. Over the next decade we must build for Canada's children and parents an early learning and child care system for the $21^{\text {st }}$ century". The idea put forth is that if we do not provide the quality ECEC programs prerequisite to an intellectually and economically thriving country, Canada's role as a world leader will be threatened.

\section{Liberal Party Platform 2006}

\section{Text analysis}

This document builds on the ideas that were introduced in the 2004 Liberal policy platform. There is approximately two and a half pages of text that address why ECEC is an important and prudent investment for the government, followed by a description of past and current ECEC initiatives by the Liberal government, and then a bulleted list explaining how the Liberals plan to pursue the existing and proposed initiatives.

The text contains elements of both strategic and communicative action, although it leans more heavily toward strategic action. Irrealis statements such as "We need to ensure that all Canadians have access to the tools to succeed", and "a national system of early learning and child care will provide parents with real options" are included to sell their policy. Other statements and phrases begin with fact and segue into prediction. For example, the beginning of the Early Learning and Child Care section reads: "In Canada today, there are over two million children under the age of six." This is a fact. It is then followed with: "These early years are the most crucial years of their life - when practically every second brings a new experience, a new chance to learn and grow. This is when much of a child's future is decided". These later irrealis statements grossly oversimplify a complex and dynamic developmental process when stating that early experiences decide a child's future. The purpose of making such a strong statement is to sell policy rather than communicate factual information. 
Having said this, there are attempts at communicative action as well. On page 28, several key pieces of information essential to making an informed vote on ECEC are presented. The fact that "1.3 million of the two million children in this country have a mother in the paid labour force", "one in five of the two million young children in Canada have access to a regulated early learning and child-care space" and that "regulation is important" (italics from document) are key pieces of objective information that this document presents. The final statement of the document lends itself to strategic action when it states: "Together we will move the vision of a national early learning and child care system from being an ideal into being a permanent and tangible component of our national social fabric". The use of the word "together" builds camaraderie with the reader as a tactic to secure the vote. As has become apparent, both strategic and communicative action are present and relied upon in this text.

\section{Discourse Analysis}

Similar to the 2004 Liberal platform, the human capital discourse is dominant in this document. In fact, the subheading for this section of the policy is "Building the Capacities of People". The international competitive market is referred to in the second line when it says: "We are investing in life-long learning so that Canadians can keep ahead of the curve". Shortly after the document states: "quality education that begins early in life prepares people to thrive in a competitive world". Earlier phrases referred to in the text analysis, such as "the early years are the most crucial years of their lives" and "this is when a child's future is decided" are further indications of the human capital discourse.

Several assumptions underlie this discourse and text. These are the same as the 2004 platform in that they include:

- Quality ECEC experience is necessary for the optimal development of children.

- Investing tax dollars into ECEC is economically prudent.

- Quality ECEC services complement parenting.

This document adds another assumption: quality ECEC is necessary for Canada to remain an internationally competitive country. Voices included in the text include the tax payer, dualincome families, employed single parent families, lower and middle-class families who currently 
cannot afford childcare and economists. Voices absent from the text are the traditional nuclear family and economically advantaged families.

The main tactic used to legitimize the human capital rationale is rationalization. Similar to the 2004 analysis, the institutional action would be putting in place the national childcare system based on the QUAD principles that would be seen as useful to the country in that they would keep Canada internationally competitive with a smarter and more productive population.

It is interesting to note that the "choice" discourse is challenged in this document. In the second last paragraph, it states: "A national system of early learning and childcare will provide parents, no matter where they live, with real options" and earlier in the document, "a national system of early learning and child care will provide parents with real options". Here, the word “options" replaces “choice". In doing this, the dependence of choice on options is emphasized. The use of the word "real" suggests that the former cannot exist without the latter. These statements subtly point out the limitations of the Conservative policy.

\section{Martin Speech, October 2004}

\section{Text Analysis}

This speech was made in reply to a speech from the throne on October 6, 2004. In this speech Martin addresses his vision for ECEC in Canada, comparing it to the significant social policy that established Medicare in Canada. The text itself is fairly formal in nature and there is little conversationalization. In this document irrealis statements are often strategically placed between realis statements. The communicative function is strategic action as the speech is essentially a sales pitch for the proposed ECEC policy.

Mr. Martin reviews the Canada Child Tax Benefit - another 1990's social policy initiative of the Liberals. After stating how this tax benefit has grown and made a difference to the children who need it most through an annual contribution of $\$ 10$ billion, Martin suggests that "our plan for early learning and child care will follow that pattern". Martin goes on to say that "it will help children be ready to learn when they start school. It will give them a tangible head start and set them on the path to lifelong achievement". These irrealis statements continue as Martin makes unqualified claims regarding the efficacy of the proposed ECEC policy to "level the playing field" and allow more parents to participate in the work force. These irrealis statements culminate 
in the final statement of the body of the text: "We believe that a strong, Canada-wide program of early learning and care for our children is the single best investment we can make in their future and in ours".

\section{Discourse Analysis}

Dominant in this text is the human capital discourse. The idea that the investment of tax dollars into ECEC programs is prudent because it will contribute to a smarter and more productive population heavily permeates this text. This discourse is embodied in phrases such as "it [national ECEC program] is the single best investment we can make in their future and in ours", "it will give them a tangible head start and set them on the path to lifelong achievement", and "it will level the playing field". These quotations also point to rationalization as the means by which the human capital discourse is legitimized. Recall that rationalization "assumes certain agreed ends, and legitimizes actions or procedures or structures in terms of their utility in achieving these ends" (Fairclough, 2003, p.99). In this case, a productive and intellectually advanced population is the agreed-upon end and a national ECEC system is the means of achieving this end.

There is also evidence of the economic discourse. Whereas the human capital discourse focuses on the long-term economic effects of an educated population, the economic discourse looks at the immediate effects of an ECEC system on the market. Martin draws on this discourse when he says: "parents who choose to participate more fully in the paid work force will be able to do so with the comfort and security of knowing their children are in a nurturing, stimulating environment."

It is interesting to note that, although not heavily emphasized, a children's rights discourse is alluded to in the opening paragraph. While the body of the speech highlights the short and long-term economic benefits to society of a national ECEC system, this first paragraph acknowledges "the lives and future of our youngest Canadians". While the "future" is indicative of the human capital discourse, using the word "lives" suggests an acknowledgement of Canadian children's current life experiences.

The key underlying assumptions that come through in the text include:

- Quality ECEC experiences are necessary for optimal development in children.

- Quality ECEC services can complement parenting 
- Quality ECEC services are important for the well-being of children right now as well as in the future.

\section{Harper Speech April 2006}

\section{Text Analysis}

This speech was given April 18, 2006 after Mr. Harper had been elected Prime Minister. At this point, the UCCB had not yet been put into effect and attempts to sell the policy were still being pursued. The venue for the speech was a family drop-in centre in Willingdon, Alberta. The speech is organized into 8 sections which are labeled: 1) Introduction, 2) Mission, 3) Five Priorities, 4) The Situation with Childcare, 5) The Liberal Strategy for Childcare, 6) The (Conservative) Government's Plan for Childcare, 7) Cutting to the Chase, and 8) Conclusion.

In the Introduction, Harper acknowledges the president of the Kids First Parent Association. This organization aims to: "promote the optimal care and well-being of children and encourage and develop a recognition of the importance of child care being provided within the home by a parent" (Kids First, 2011). Although the specific goals of the association are not addressed in the speech, Harper praises Kids First as "a laudable organization - an organization whose foremost focus is what is best for our children". Hence, although it is not directly said, this speech begins with a statement that supports the idea that in-home care by a parent is best for Canadian children.

Conversationalization is heavily relied on throughout all sections of this text. Whereas the Martin speech has a formal tone and approach to the issue, Harper's speech relies on informal, colloquial language. When making his address, Harper refers to his listeners as "my friends" at three different points during the speech. This puts forth a tone of camaraderie. When addressing section four, the situation on childcare, Harper begins by trying to identify with the audience. He says, "As a husband and father with young children, I am particularly aware of the challenges young families face". The use of this phrase again creates an atmosphere of understanding, with Harper trying to portray the idea that he also belongs to the in-group of struggling parents.

Other quotes from this text which provide evidence of conversationalization include: "and since the election they [the Liberal party] have been beating their chests on the [ECEC] issue", and "over the past 13 years we've been treated to a lot of fancy words on childcare". In 
fact, Harper undermines the use of formal and accurate language in the last quote by referring to such talk as "fancy words".

This speech also relies heavily on irrealis statements, recontextualized information and rhetorical questions. Realis statements that are included tend to leave out key pieces of information. For example, in section five where the Liberal strategy for childcare is reviewed, Harper states: "But for all their talk, they [the Liberals] have precious little to show for it. Their national child care program never materialized". It is true that the Liberal program never materialized, but that is because the Conservatives were in the process of phasing out the bilateral agreements with the provinces and the funding that had been allocated for the ELCC Foundations program.

Rhetorical questions, prefaced by irrealis statements, are another textual technique employed in this text. For example, Harper states: "The question that the opposition must answer is simple. Do they support the $\$ 1200$ allowance for children, or do they support the status quo in other words, nothing at all?", and again a few lines later, "Does the opposition support giving parents $\$ 1200$ per child per year or do they prefer the status quo - which is zero?” Both of these rhetorical questions include an irrealis statement suggesting the Liberals had proposed "nothing at all" and" zero" to parents in need of childcare.

The word "choice" is also nominalized throughout this document. In fact, at the time of this speech, the name of the UCCB was the Universal Choice in Child Care Benefit. In this context, the "choice" was again meant to mean freedom rather than addressing the specific creation of new childcare options that were not in existence prior to the policy.

\section{Discourse Analysis}

Not only is the "choice" discourse dominant in this text, there is no evidence of other key discourses in this debate. The word "choice" is used 8 times throughout the document. In addition to repetition, an appeal to traditional moral values is relied on to legitimize this discourse. The ideological belief that the government should not interfere with the private, family responsibility of childcare is evidenced through referring to such government involvement as the "bureaucratic middleman". Recontextualized information is also used to support the "choice" discourse. For example, Harper states: "It [UCCB] acknowledges and supports the two thirds of parents who do not use 9-5 institutional day care". Besides the fact that the word "institutional" casts a negative shadow on childcare outside the home, the statistic itself has been taken out of its 
original context and the original context is not cited. This questions the validity and reliability of such numbers. Furthermore, it is important to keep in mind that there are not enough spaces for even $1 / 3$ of children in regulated childcare centres in Canada. While the use of these figures appears to support the "choice" discourse, upon analysis, this is not the case.

There is very little dialogicity in this text. The voice of two-parent, nuclear families with a stay-at-home parent dominates. The voices of dual income families, single parent families, families with limited resources, young families, childcare advocates and experts as well as children themselves are absent from this text. The human capital, economic, and children's rights discourse are completely absent. Instead, the idea that parent choice in childcare is more important than any other aspect of childcare dominates. Furthermore, it is assumed that "our new approach enhances parental choice". Not only is choice in childcare portrayed as ideal, this speech also infers that the UCCB will enable actualization of that choice.

The "choice" discourse is legitimized through an appeal to traditional moral values. The belief that the state should not interfere with matters pertaining to child-rearing comes across. 


\section{Discussion}

\section{Review of the "choice" discourse}

The "choice" discourse is rooted in the idea that it is solely a parent's right and responsibility to provide and/or find ECEC and that intervention from the state in this process undermines the abilities of parents. It is based on a traditional family rationale and consistent with a conservative welfare regime that supports little government involvement in the private domain of family life. In the case of the 2006 election, the "choice" discourse is used to support the Universal Child Care Benefit. This benefit provides cash to parents to spend on childcare with no restrictions as to how or where the money is spent. The idea that a parent's first "choice" in ECEC would be actualized with the introduction of the UCCB was used to sell the Conservative policy.

As has been discussed earlier, this discourse is based on four fundamentally flawed practical assumptions. The first assumption is that $\$ 100$ a month is sufficient to make a difference in childcare options for parents. The fact is that quality, regulated ECEC for a child under six years old costs substantially more than $\$ 1200$ a year. In fact, $\$ 1200$ can easily be spent on one month of ECEC for a child under the age of 2 in urban areas in Canada.

The second flawed assumption of the "choice" discourse is that quality ECEC spaces do exist for those who can pay. The reality is that there is a severe lack of quality ECEC spaces for even those who can afford high parent fees. Developing and maintaining high quality childcare is very difficult for individual parents to take on.

Third, over time it has become apparent to many parents that the UCCB rarely turns out to be $\$ 1200$ per year due to the fact that it is a taxable benefit. The only parents who receive the full $\$ 1200$ a year for each child under six are those in the lowest income bracket and/or families who have a stay-at-home parent.

Finally, a maximum of $\$ 1200$ a year is not enough money to offer working parents the option of staying home. It is obvious that single parents would certainly not have the option of staying home with their child for $\$ 100$ a month. It is thus apparent that the UCCB does not offer, or contribute to, choice in ECEC for the large majority of Canadian parents.

What the UCCB offers parents in ECEC is akin to what a shiny new quarter offers a child at an under-stocked candy store. The shiny quarter is inherently enticing to a child who anticipates being able to choose whatever kind of candy he or she wishes. No child would refuse 
the money. However, he or she would be greatly disappointed to arrive at the candy store to find half-stocked shelves of day-old candy. It would be a further disappointment to realize that the only sweets the quarter could buy are a couple unattractive, stale candies. Similarly, parents were and still are eager to receive money from the government. The sobering reality that this money has little to no effect on the accessibility of quality ECEC in Canada has become apparent only after the fact. Sadly, choices in childcare have not been expanded nor has quality ECEC become more accessible and affordable since the introduction of the UCCB. With the funding from the ELCC program having ended in the 2006/2007 fiscal year, the metaphorical candies in the store are becoming less and less appealing. Those who want candy must simply take what they can get - if anything at all. Finding oneself in this situation is the very antithesis of consumer preference as promoted by the "choice" discourse.

\section{Was the "Choice" Discourse Dominant?}

The results presented in this study show that the "choice" discourse was dominant in the media: it was present more often than not in newspaper articles addressing ECEC throughout December 2005 and January 2006. In The Globe and Mail 71\% of relevant articles included the "choice" discourse. In The National Post, 65\% of relevant articles contained the "choice" discourse. The CDA of Harper's speech and the 2006 policy platform of the Conservative Party also show that the "choice" discourse saturated the text. In fact, the only texts included in this analysis where the "choice" discourse was not dominant were the Liberal Party platforms and Mr. Martin's speech.

Rogers (2004) states: "Let us call discourses that lead to social goods in a society dominant discourses, and let us refer to those groups that have the fewest conflicts when using them as dominant groups" (p.6). Rogers (2004) further points out that one can support several different, sometimes opposing, discourses. For example, one may believe that parents have the responsibility of choosing and securing care for their children while also believing that all children have a right to high quality ECEC. Such a person would therefore experience some conflict when using the "choice" discourse. Lakoff (2006) refers to individuals who hold opposing ideologies and appreciate conflicting discourses as "biconceptuals".

Biconceptuals may experience conscious and/or unconscious conflict when using or supporting dominant discourses since they possess values consistent with one or more discourses. On the other hand, dominant groups experience little conflict when using dominant discourses (Rogers, 2004). In this case, Stephen Harper and the Conservative Party would be the dominant 
group who created and repeatedly used the "choice" discourse - evidently exhibiting little conflict when relying on this discourse to acquire votes and achieve power.

Fairclough (2003) states that: "Discourse, including the dominance and naturalization of particular representations, is a significant aspect of hegemony, and struggle over discourse a hegemonic struggle" (p.218). Recall that hegemony is defined as the acquisition of power by consensus rather than force. When a discourse becomes dominant, people buy willingly into this one way of representing the issue largely because other ways of viewing the issue are absent. Thus the underlying ideological assumptions on which this representation is based become accepted and go largely unchallenged. That this occurred is evident in the dominant presence of the "choice" discourse in newspaper articles throughout the election campaign. Discourses other than the "choice" discourse were rare. Other than in the policy platforms of the Liberal Party and Mr. Martin's 2004 speech, alternative discourses such as the human capital and/or child's rights discourse faded into the background. Since the majority of Canadians do not read policy documents themselves and instead rely on the media to portray key messages, the dominance of the "choice" discourse and relative absence of other discourses threatened Canadians" understanding of the ECEC issue. Instead, the "choice" discourse's appeal to the abstract idea of freedom replaced a comprehensive understanding of how these two ideas were or were not related.

It is also interesting that it is the blend of a conservative and prototypical liberal model of welfare capitalism that gives birth to the "choice" discourse. As is consistent with a conservative ideology, there is a strong appeal to traditional family values. The idea that it is most natural and/or acceptable for the family, usually the mother, to provide care for children prevails. Esping-Anderson (1999) points out that in a conservative welfare regime it is common that "family benefits encourage motherhood" (p.27). That the UCCB most heavily benefits families with a stay-at-home parent is consistent with a conservative regime.

On the other hand, a prototypical liberal regime also comes into play as a result of the UCCB. When the family does not provide ECEC (as is considered ideal in a conservative regime), responsibility is placed on the market to provide services. As such, ECEC becomes a commodity to be purchased and sold. Once ECEC is commodified, it can no longer be considered a "right" of the people - in this case, the children. Instead, it is a good awarded to those who can afford and purchase it. It has repeatedly been found that the pathologies in the ECEC market are 
great (Vincent \& Ball, 2006, Cleveland \& Krashinksy, 2004). Under the Conservative policy, when the family cannot provide, the market becomes the alternative without a meaningful contribution from the state. Given that mothers' labour force participation in 2007 was $69 \%$ for children 0-2 year and increased up to 84\% when children 6-15 years were added (Beach et al, 2009), stay-at-home mothers are not the norm. Although traditional family values may be appealing to some, they are simply not practical for most of Canada's families. There is a fundamental mismatch between these values and the realities of Canadian families requiring childcare in the $21^{\text {st }}$ century.

\section{What Were the Other Discourses?}

As was stated above, the "choice" discourse was dominant in the 98 newspaper articles reviewed, the Conservative platform and Harper's speech. The other important discourse that was largely unacknowledged by the media was the human capital discourse. The human capital discourse was dominant in documents produced by the Liberal party. This discourse is based on the ideological assumptions that educated and productive individuals are able to secure the opportunities and commodities necessary for their well-being.

When referring to the population, phrases such as "the key to success in today's global economy is education" and "investment in childcare and early learning is the key to success in the $21^{\text {st }}$ century economy" were used. The idea that the long-term stability of our country as a world leader could be threatened if Canada fails to invest in ECEC comes through in the texts produced by the Liberal Party. In reference to the individual, the human capital discourse is used to support ideas such as: "these early years are the most crucial years of their lives - this is when much of a child's future is decided" and "future achievement is set in early childhood". The wellbeing of the individual and the collective is measured by achievement, market success and the opportunity that is born of these.

The child right's discourse was almost entirely absent from the texts analyzed. This discourse acknowledges the current needs, values and voices of children and was only identified once (in passing) in the texts examined. More commonly, when children's rights were referred to they were discussed in terms of future opportunity and success rather than as acknowledgment of rights currently promised to children in Canada as a result of the UN Convention on the Rights of the Child. Social democratic countries, such as the Nordic countries, rely on this discourse to support the significant funding to quality ECEC services. Sadly, this discourse was completely 
neglected throughout the 2006 election and receives little ECEC policy attention in Canada today.

\section{What Textual Processes Were Used to Make the "Choice" Discourse Dominant?}

Unique to this study was its in depth look into the textual and discourse processes used by the Conservatives to make the "choice" discourse dominant. An awareness of these processes on the part of the reader helps one critically process mass-produced documents written to communicate essential information. With a critical lens, consumers of text have the opportunity to bring into awareness textual and discourse processes that may directly influence their understanding of the issue at hand and their decision making related to that information.

\section{Strategic Versus Communicative Action}

It quickly became apparent through a CDA of all nine documents that strategic, rather than communicative, action saturated the texts. Recall that strategic action "encourages people to act in ways which are oriented to achieving results" (Fairclough, 2003, p.110) whereas communicative is "oriented to reaching understanding" (Fairclough, 2003, p.110). Strategic action at the expense of communicative action in an election is indeed concerning given that the campaign becomes a venue for selling policy rather than informing the people about the policy. Furthermore, elections are unique in that a great deal of power is at stake. In a democratic society, critical information on election issues must be effectively and clearly communicated to ensure that voters make an informed voting decision. It is one thing to use strategic action when selling commodities such as cars, computers, or beer and popcorn, as the consequences of being misinformed do not threaten the well-being of citizens. It is quite another when strategic action is used to sell policy on which people's daily lives depend. Fairclough (2003) states: "What is problematic, and indeed potentially 'pathological', is the over-extension of strategic action as part of the 'colonization' of the lifeworld by systems" (p.111). In other words, when strategic action is used by dominant groups to secure power over vulnerable groups the balance of power in our society is pathologized. Individuals do not have the information they need to assert the power they do have - their vote. Conversationalization, nominalization and recontextualization are the three concrete textual and discourse processes indicative of strategic action that were relied on in the majority of the analyzed texts. 


\section{Conversationalization}

This study has shown that the producers of texts often use colloquial and conversational language, as opposed to formal and specific language. This is to be somewhat expected in newspaper articles, which often use catchy language with the fewest number of words to capture attention of and get the message out to a busy reader. Indeed, Fairclough (1995) states that "media are being more fully drawn into operating on a market basis with the 'leisure' industry, and one part of that is greater pressure to entertain even within public affairs output" (p.11). Indeed, the primary goal of newspapers is to sell papers - not policy. Attracting and keeping readers is fundamental to their success. It has been shown that the combination of this with the politicians' goal of getting votes often leads to a lack of authenticity and comprehensive dissemination of information related to important policy issues during an election.

What is more interesting was the frequent use of conversationalization in policy documents and political speeches of the Conservative party. Mr. Harper repeatedly referred to his audience in his 2006 speech as "my friends". Such an informal address creates an atmosphere of camaraderie with receivers of the text. Once this tone had been created, Harper then put forth rhetorical questions prefaced by irrealis statements in this casual tone. For example, he asks: "do they support the $\$ 1200$ allowance for children or do they support the status quo - in other words, nothing at all?" Here, he refers to the comprehensive plan of the Liberal Party along with the substantial financial commitment as "nothing at all". In the Conservative policy platform, colloquial language is again used to describe the Liberal plan. Instead of referring to their plan as what it is, a national ECEC strategy, the Conservatives refer to it as a "massive childcare bureaucracy". The use of these casual words in the context of a formal policy document is misleading and concerning. Instead of focusing on the function of the document, which is to communicate one's own policy initiative, this document demonized the Liberal plan with colloquial and inaccurate language. Harper's goal was clearly not to genuinely inform his audience but rather to sell his policy.

There was little evidence of conversationalization in the Liberal platforms. Instead, the policy documents overall incorporate accurate, official language and the documents tend to explain the ideas and reasons behind the policies. This is evident in the mere length of the policy documents that is devoted to the ECEC issue. Whereas the Conservative platform includes approximately three paragraphs of text devoted to the issue, the Liberal platform devotes three 
pages in both the 2004 and 2006 elections to ECEC. Both Liberal platform documents review past ECEC initiatives that have or have not been effective at addressing the issue while placing ECEC in an international context through drawing on examples from other developed countries with comprehensive ECEC policies. The word count and formalized language used throughout the Liberal documents are evidence of communicative rather than strategic action.

\section{Nominalization}

Nominalization is an effective textual process used in several of the documents that contributed to the dominance of the "choice" discourse. Nominalization is a type of grammatical metaphor that occurs when a verb or phrase is converted into a noun in order to confuse agency and responsibility for the action (Fairclough, 2003). "Choice" was repeatedly nominalized in most of the articles examined in both Part I and Part II of this analysis. When "choice" is nominalized, who is doing the choosing and the options to choose from are overlooked. The result of this is that "choice" becomes a metaphor for individual freedom.

The "choice" discourse depends on the nominalization of the word "choice". This is evident in the original name of the Conservative policy proposal - the "Universal Choice in Childcare Benefit". The original name of this policy capitalizes on nominalization by overlooking what the options are to choose from. Appealing to the widely celebrated value of freedom was understandably very popular and successfully contributed to the Conservative's sale of their policy.

The word "choice" is frequently nominalized when used in other contexts as well. For example, The Globe Article 1 states; "families need choice in terms of daycare and that families in which one parent stays at home with the kids deserve help too". The irony here is that "choice", nominalized to mean "freedom", is used to support the policy that actually does the least to actualize the availability of options. As has already been established, the UCCB does not allow parents the added option of staying home with their children given it is only, at most, $\$ 100$ a month. In fact, the UCCB actually restricts freedom to parents because it is not enough money to cover the cost of care by anyone other than family or friends, is not enough to allow one to exit the work force, and was being proposed as a replacement for the funding desperately needed to create the lacking ECEC spaces in Canada.

The fact that "choice" is nominalized in the context of the "choice" discourse and the "choice" discourse appeared in $65 \%$ of articles in The Globe and $71 \%$ of the articles in The Post 
in addition to the Conservative platform and Harper's speech, is troubling. It is concerning to think that a grammatical metaphor could have played such a major role in influencing people's thinking about a policy issue so pertinent to the well-being of society's most vulnerable members - our children. The reality of the policy contradicted the premise on which the policy was being marketed. Parents' choices in ECEC arguably became fewer as a result of the UCCB due to the decreased funding to the creation and maintenance of regulated of ECEC spaces and an ECEC system. Furthermore, the cuts to childcare funding that the provinces had been expecting to receive as transfer payments came at a time when women's participation in the workforce was at an all-time high.

\section{Recontextualization}

Recontextualization is a discourse process that was also relied on to contribute to the dominance of the "choice" discourse. This was most apparent in the frequent recontextualization of Scott Reid's comment initially made on a CBC television interview. Recall that recontextualization involves the "movement [of text] from one context to another, entailing particular transformations consequent upon how the material that is moved figures within the new context" (Fairclough, 2003, p.51). In the case of this comment, the recontextualization is also an example of genre mixing given that text is moved from the context of a television interview to text in a newspaper. Television and print are two fundamentally different genres of communication. A television interview is casual and conducted as an informal conversation. Newspaper articles, although often saturated with colloquial language, offer the opportunity to the author to more thoroughly plan what will be said and how it will be said. Consequently, when phrases and language are recontextualized into a newspaper article, the text may be interpreted more literally than was intended. Scott Reid's comment is a prime example of both conversationalization and recontextualization gone wrong.

The original comment made by Scott Reid on the television interview on CBC was: "Working families need care. They need care that's regulated, safe and secure. And that's what we're building here. Don't give people \$25 bucks to blow on beer and popcorn. Give them childcare spaces that work." This full, direct quote was referred to only in The Globe Article 1. In this article, the reader was informed of the reasons why Reid said this in addition to acknowledging Reid's apology for making the "dumb" comment. The point that Reid was trying to make, that $\$ 25$ a month was insignificant to making a difference in childcare choices, was lost 
with the use of Reid's colloquial example of what $\$ 25$ a week could buy for parents - "beer and popcorn". In essence, it was interpreted to mean that parents are untrustworthy and would spend money allocated to ECEC on frivolous extras for themselves.

The Conservative Party seized the opportunity to vilify Reid and the Liberal Party. Reid's conversational language was generalized and inaccurately interpreted to mean that Canadian parents are irresponsible and cannot act in their child's best interest. The newspaper article in The Post was titled Scott Reid's Canada and painted the Liberal party as being "paternalistic" in that "bureaucrats know better than parents what is best for children". The quote itself was recontextualized as it read: "if child-care money were under the control of parents themselves, they [parents] would simply 'blow it on beer and popcorn"”. The recontextualization and paraphrasing of the original quote in this article thus portrays it to mean something entirely different than Reid was saying. Further hurting the Liberal Party, Reid's apology for the comment was also misrepresented. That Reid was apologizing for his word selection comes through in the article in The Globe whereas the article in The Post suggests that Reid was apologizing for undermining parent's abilities - something he never actually intentionally did. It becomes evident that recontextualization was used to strategically influence the reader's understanding of the issue rather than to genuinely inform the reader.

\section{Discourse and Framing: Text production and Text Consumption}

This analysis has focused primarily on text production - that is, identifying textual and discourse processes. It is important to concurrently recognize the role of text consumption, or how text comes to be understood and hold meaning, to appreciate the full impact of text on a population's understanding of an issue. Cognitive psychologist George Lakoff, who has worked extensively on social policy, defines framing as "mental structures that allow human beings to understand reality - and sometimes create what we take to be reality" (Lakoff, 2006, p.18). Lakoff has developed the concept of how frames shape the way human beings understand and/or process information related to politics. Frames and discourse are closely related concepts. Both are based on ideological foundations that are seldom spoken, but unconsciously influence our perception of reality. Whereas this analysis has focused primarily on discourse in that language features and textual processes have been identified, framing delves deeper into the cognitive processes that translate text into understanding. 
It has become apparent in this analysis that in order for discourses to hold power and create influence, they must become dominant. The analysis has further demonstrated that the "choice" discourse was dominant throughout mediated texts in the 2006 federal election and that one of the key means of legitimizing this discourse was through an appeal to moral values. The Liberals framed the issue practically whereas the Conservatives framed the issue emotionally. The Conservatives relied on techniques appealing to moral values and deep-rooted emotions whereas the Liberals relied on objective, and logical facts. Interestingly, the human capital discourse failed to become dominant. This is consistent with Lakoff's research arguing that the thinking of human beings is often ideological rather than rational when it comes to policy. Lakoff (2006) points out that much of human thought is in fact irrational - or not based on a logical, objective way of viewing the world. Indeed, our emotions and ideological values often trump our rational mind.

With this insight, it is not particularly surprising that in the case of childcare in the 2006 federal election textual and discourse processes such as nominalization and conversationalization were effective contributors to the dominance of the "choice" discourse. Apparently, communicating empirically supported ideas such as the higher quality of not-for-profit centres and demographic information citing the increased participation of mothers in the workforce does not have the same impact as appealing to the abstract value of freedom or the emotional security provided through identification with the politician.

Lakoff (2006) discusses the role of identity and authenticity in texts. As this quote in the beginning of this paper suggests, politics is about identifying with politicians, seeing the world through their eyes and genuinely believing one's own values are congruent with those of their leader. Although camaraderie and solidarity was drawn upon by Conservatives throughout the election through the use of phrases such as "my friends" to refer to the public and the attempt of Harper to portray himself as "one of the people", the role of authenticity truly came to a peak with the recontextualization of Scott Reid's "beer and popcorn" comment. Reid's intentions were innocent and actually in the objective and logical best interests of Canadian parents, however, his apology and attempt at taking back his words (admitting it was "dumb" way to make his point) completely undermined his authenticity. As Lakoff (2006) states:

Authenticity matters in politics. When you surrender authenticity, you surrender your values, and you surrender trust... when your values are not currently popular, being 
authentic means having courage. Being courageous does not mean being unwise, or offending one's constituents (p.16).

While Reid's comment was taken out of context and came to mean something entirely different than it had in its original genre, Reid was naïve in not considering adequately how his selection of words could negatively impact his - and the Liberals' - public image. He had the courage to speak out, which is admirable and respectable as his ideas were going against the dominant discourse, but he did so in a manner detrimental to both himself and his party. Thus, the cost of this comment was significant as it not only undermined the legitimacy of the Liberal childcare strategy, but also undermined the integrity of the Liberal party. Although a CBC poll taken right after the 2006 election found that only $2 \%$ of the Canadian population voted based on the childcare issue, the fact is that this issue may have contributed to the destruction of Liberal authenticity and moral integrity.

\section{Conclusion}

Through text embedded in strategic action, the "choice" discourse became dominant and achieved what it set out to do in the 2006 federal election. The Conservative Party was elected and the UCCB was implemented. This CDA has revealed how the "choice" discourse was used to sell a policy that contradicted the very premise on which the policy was sold. Through nominalization, recontextualization and conversationalization, the "choice" discourse was successful at appealing to the idea of freedom in spite of the logical and rational limitations of the policy. The Conservative policy proposal was consistently framed to reflect the traditional family values and love of individual freedom present in a welfare state that is a blend of conservative and liberal democratic regimes. The more concrete framing of the Liberal Party's platform did not have the same emotional appeal to the voter and allowed the Conservatives to portray the Liberals' ideal ECEC policy as providing for a "paternalistic bureaucracy". This may have played a role in the defeat of the party that would, in fact, have worked to establish a national ECEC program and increased choice in regulated childcare in Canada.

Today, Canada's international ratings on ECEC services continue to lag in comparison to other developed nations. There is a space for only $18.6 \%$ of $0-12$ year old children in Canada in regulated childcare (Beach et al, 2008). Choice is being provided through market produced childcare facilities that are too expensive for many Canadian families. Canada's first homegrown chain of corporately owned childcare centres (Edleun) is now trading on Toronto's venture 
stock exchange. Other for-profit, privately held childcare companies, such as Kids and Company, have also grown significantly since the Conservatives took office. Empirical research has repeatedly shown that for-profit centres are generally of poorer quality than non-profit and publicly funded ECEC programs (Cleveland \& Krashinsky, 2004, 2007). However, federally transferred funding needed for the creation and maintenance of publicly funded and regulated child care spaces fell to $\$ 600$ million in 2008 compared to $\$ 725$ million in $2005 / 06$ and $\$ 900$ million in 2006/07 (Beach et al, 2008).

Once the UCCB was enacted and the ELCC Foundations program cancelled, national ECEC services and policy largely fell off the political agenda. There has been some provincial activity in ECEC, such as the full-day learning/kindergarten in Ontario, but overall ECEC remains primarily a private, family responsibility. The result of this is that families in which there is a parent or family member to care for the child at little or low cost are best off. Families with sufficient income to access quality care are also privileged. The majority of Canadian families continue to struggle to access the ECEC needed for children in the years prior to starting school as well as for school-aged children during after-school hours.

Although a majority Conservative government has recently been elected, with Stephen Harper as its Prime Minister, the need for quality ECEC in Canada cannot be ignored. Research clearly indicates the importance of quality, publicly funded, not-for-profit ECEC during the early years and this CDA confirms the importance of genuine choice in ECEC to Canadians.

In a democracy we do have a right to know the facts. The problem is in securing factual information. This becomes a very demanding and complex process beyond the capability of most citizens and allows political parties and analysts to become and remain dominant. Since the authors of many articles appear to be interested primarily as political reporters rather than as ECEC consumers or advocates, the facts inevitably become bias and the ability of the regular reader to understand the issue and act on it becomes further restricted. The media cannot be counted on to promote ECEC since its prime goal has always been and will continue to be the sale of its text. So while the desire and need for choice in ECEC is important to the majority of Canadians, social policy will continue to be framed and developed by politicians. Hopefully, in the future more politicians will recognize the potential value of ECEC.

It is time to move from metaphorical discussions of "choice" to meaningful policy change. Yes, parents should have a real choice in ECEC. Yes, it is good for our country and 
economy if we have an educated and productive population. Yes, investing in ECEC will yield an instant boost in the economy due to job stimulation and increased participation of mothers in the workforce. Most importantly however, we owe it to our children to ensure that they are cared for in a safe, nurturing and stimulating environment. This means regulating quality of care and creating and subsidizing spaces that will provide for child rights as promised almost thirty years ago in the Convention on the Rights of the Child. 


\section{Appendix A}

\section{Conversationalization}

Occurs when formal, public documents embrace speech that would be typical of everyday language. This technique breaks down the barrier between information and entertainment as well as public and private spheres. A concrete example would be colloquial vocabulary and idioms.

\section{Speech function}

Consists of demand, offer, question or statement.

Statements are further categorized into:

- Realis: Statements that can be considered fact - what is, was, or has been the case (Fairclough, 2003, p.109).

- Irrealis: Statements that are hypothetical or predictive in nature (Fairclough, 2003, p.109).

- Evaluation: Statements that possess implicit or explicit judgments based on value assumptions (Fairclough, 2003, p.215).

Speech function may also be oriented towards:

- Strategic action: Speech functions that encourage people to act in ways which are oriented to achieving results (Fairclough, 2003, p.110)

- Communicative action: Action which is oriented to reaching understanding (Fairclough, 2003, p.110)

\section{Nominalization}

"A type of grammatical metaphor which represents processes as entities by transforming clauses (including verbs) into a type of noun...It is a resource for generalizing and abstracting which is indispensible in, for instance, science, but can also obfuscate agency and responsibility" (Fairclough, 2003, p.220)

\section{Intertextuality}

"The presence within the text of elements of other texts (and therefore potentially other voices than the author's own) which may be related in various ways" (Fairclough, 2003, p.218). 
Dialogicity is a closely related concept. This refers to the extent to which other voices are

"represented, and responded to, or conversely excluded or suppressed" (Fairclough, 2003, p.214).

\section{Legitimation}

"A widespread acknowledgement of the legitimacy of explanations and justifications for how things are and how things are done" (Fairclough, 2003, p.219)

\section{Rationalization}

"Legitimization by reference to the utility of institutionalized action" (Fairclough, 2003, p.98)

\section{Recontextualization}

"A movement from one context to another, entailing particular transformations consequent upon how the material that is moved figures within the new context" (Fairclough, 2003, p.51). 


\section{References}

Albanese, P., Rauhala, A., Ferns, C., Johnston, J., Lam, J., \& Atack, E. (2010). Hiding the elephant: Child care coverage in four daily newspapers. Journal of Comparative Family Studies, 41(5), 817-836.

Albanese, P., Rauhala, A., Ferns, C., Johnston, J., Lam, J., \& Atack, E. (2011). Who says what. Forthcoming in the Journal of Child and Family Studies.

Beach, J., Friendly, M., Ferns, C., Prabhu, H., \& Forer, B. (2009). Early Childhood Education and Care in Canada 2008. Toronto, Ontario: Childcare Resource and Research Unit.

Canadian Centre for Policy Alternatives. (2006). Moving forward: An alternative federal budget 2006. Retrieved February 1, 2011 from

http://www.policyalternatives.ca/publications/reports/alternative-federal-budget-2006

CBC News. (2005). Liberal apologizes for saying Harper day-care bucks may buy beer, popcorn. Retrieved Feb. 22, 2011 from http://www.cbc.ca/news/story/2005/12/11/daycare051211.html.

Child Care Human Resources Sector Council. (2009). Literature Review of Socioeconomic Effects and Net Benefits: Understanding and Addressing Workforce Shortages in Early Childhood Education and Care (ECEC) Project. Retrieved February 1, 2011 from http://www.ccsc-cssge.ca/uploads/WFS\%20LitReview\%20-\%20Socio\%20$\% 20 F I N A L . p d f$

Cleveland, G., \& Krashinksy, M. (2004). Child Care for a Change: Shaping the $21^{\text {st }}$ Century, Winnipeg November 12 - 14, 2004. Ottawa, Ontario: Canadian Council on Social Development.

Cleveland, G., \& Krashinksy, M. (2004a). The Quality Gap: A study of Nonprofit and Commercial Child Care Centres in Canada. Toronto, Ontario: University of Toronto at Scarborough, Division of Management.

Cleveland, G., \& Krashinksy, M. (1998). The Benefits and Costs of Good Child Care: The Economic Rationale for Public Investment in Young Children- A Policy Study. Toronto, Ontario: Childcare Resource and Research Unit.

Collier, C., \& Mahon, R. (2008). One step forward, two steps back: Child care policy from Martin to Harper. In A. Maslove (2008) (Ed.), How Ottawa Spends, (pp.110-133).

Conservative Party of Canada. (2006). Stand up for Canada: Conservative Party of Canada Federal election platform 2006. Retrieved February 1, 2011 from http://www.cbc.ca/canadavotes2006/leadersparties/pdf/conservative_platform20060113.p df

Doherty, G., Lero, D., Goelman, H., LaGrange, A. \& Tougas, J. (2000). You Bet I Care! Guelph, Ontario: Centre for Families, Work and Well-Being. 
Doherty, G., Friendly, M., \& Beach, J. (2003). OECD Thematic Review of Early Childhood Education and Care: Canadian Background Report. Ottawa, Ontario: Government of Canada.

Esping-Anderson, G., (1999). The Three Worlds of Welfare Capitalism. Princeton, New Jersey: Princeton University Press.

Fairclough, N., (1995). Media Discourse. New York: Bloomsbury.

Fairclough, N. (2003). Analyzing Discourse: Textual analysis for social research. London: Routledge.

Fairholm, R. (2011). Early Learning and Care Impact Analysis. Toronto, Ontario: OISE/University of Toronto. Atkinson Centre for Child Development.

Fortin, P., Godbout, L., \& St-Cerny, S. (2011). Economic Consequences of Quebec's Educational Childcare Policy. OISE: Early Years Economics Forum. Toronto, Ontario. Retrieved July 3, 2011 from http://childcarecanada.org/documents/research-policy-practice/11/06/earlyeducation-economic-forum.

Friendly, M. (2006). Canadian early learning and child care and the Convention on the Rights of the Child. Toronto, Ontario: Childcare Resource and Research Unit, University of Toronto.

Friendly, M., \& Prentice, S. (2009). About Canada: Childcare. Winnipeg, Manitoba: Fernwood Publishing.

Government of Canada, (2006). The Budget Speech 2006: Focusing on Priorities. Department of Finance. Retrieved January 31, 2011 from http://www.fin.gc.ca/budget06/speech/speecheng.asp

Lakoff, G., (2006). Thinking Points: Communicating Our American Values and Vision. Farrar, Straus and Giroux: New York. Retrieved July 15, 2011 from http://www.cognitivepolicyworks.com/resource-center/thinking-points/.

McCain, M., \& Mustard, F. (1999). Reversing the real brain drain: Early years study. Toronto, Ontario: The Canadian Institute for Advanced Research.

Moss, P. (2008). Early Childhood Education Markets and Democratic Experimentalism: Two models for early childhood education and care. Discussion paper: Bertelsmann Stiftung. Retrieved July 10, 2011 from http://www.bertelsmannstiftung.de/bst/de/media/xcms_bst_dms_24015_2.pdf

Office of the United Nations High Commissioner for Human Rights, (1989). Convention on the Rights of the Child. Retrieved March 10, 2011 from http://www2.ohchr.org/english/law/crc.htm. 
Organization for Economic Co-operation and Development, (2006). Starting Strong II: Early childhood education and care. Directorate for Education. Paris: Author.

Organization for Economic Co-operation and Development, (2004). Canada: Country NoteEarly Childhood Education and Care Policy. Paris: OECD Directorate for Education, Organization for Economic Co-operation and Development.

Rinehart, D. (2008). Baby talk: How gender issues affected media coverage of the child-care debate in the last federal election. Canadian Journal of Media Studies, 4(1), 1-40.

Rinehart, D. (2007). The daycare campaign revisited: From baby steps to beer and popcorn. Policy Options, 29(7), 47-52.

Rogers, R. (2004). An introduction to critical discourse analysis in education. In R. Rogers (Ed.), An Introduction to Critical Discourse Analysis in Education (pp.173-205). Mahwah, NJ: LEA.

Sauve, T. (2003). Contemporary Family Trends: The Current State of Canadian Family Finances - 2003 Report. Ottawa, Ontario: The Vanier Institute of the Family.

The Strategic Council, (2005). Canadian Impressions of Federal Political Leaders. Retrieved February 1, 2011 from http://www.thestrategiccounsel.com/our_news/polls.asp.

UNICEF. (2008). The Child Care Transition: A League Table of Early Childhood Education and Care in Economically Advanced Countries. (Report Card 8). Florence: UNICEF Innocenti Research Centre.

van Dijk, Teun A., (1993). Principles of critical discourse analysis. Discourse \& Society, 4(2), 249-283.

van Diijk, Teun, A. (1995). Aims of Critical Discourse Analysis. Japanese Discourse, 1, 17-27.

van Dijk, Teun A., (2003). Critical discourse analysis. In Schiffrin, D., Tannen, D., \& Hamilton, H. (Eds.), The Handbook of Discourse Analysis (pp.352-371). Malden, MA: Blackwell Publishing Ltd.

Vincent, C, \& Ball, S. (2006). Childcare, Choice and Class Practices: Middle-class parents and their children. London: Routledge.

Woodside-Jiron, H. (2004). Language, power and participation: Using critical discourse analysis to make sense of public policy. In R. Rogers (Ed.), An Introduction to Critical Discourse Analysis in Education (pp.173-205). 